\title{
Evaluation of Cloud Fraction Simulated by Seven SCMs against the ARM Observations at the SGP Site*
}

\author{
HuA Song, ${ }^{+}$Wuyin Lin, ${ }^{+}$YANluAn Lin,,${ }^{\#}$ Audrey B. Wolf, ${ }^{@}$ LeO J. Donner,,${ }^{\&}$ \\ Anthony D. Del Genio, ${ }^{* *}$ Roel NegGers, ${ }^{++}$SAtoshi Endo, ${ }^{+}$And YANGANG LiU $^{+}$ \\ ${ }^{+}$Brookhaven National Laboratory, Upton, New York \\ \# Ministry of Education Key Laboratory for Earth System Modeling, Center for Earth System Science, \\ Tsinghua University, Beijing, China \\ ${ }^{\circledR}$ Columbia University, New York, New York \\ ${ }^{\&}$ NOAA/Geophysical Fluid Dynamics Laboratory, Princeton, New Jersey \\ ** NASA Goddard Institute for Space Studies, New York, New York \\ ${ }^{++}$Royal Netherlands Meteorological Institute, De Bilt, Netherlands
}

(Manuscript received 9 September 2013, in final form 2 June 2014)

\begin{abstract}
This study evaluates the performances of seven single-column models (SCMs) by comparing simulated cloud fraction with observations at the Atmospheric Radiation Measurement Program (ARM) Southern Great Plains (SGP) site from January 1999 to December 2001. Compared with the 3-yr mean observational cloud fraction, the ECMWF SCM underestimates cloud fraction at all levels and the GISS SCM underestimates cloud fraction at levels below $200 \mathrm{hPa}$. The two GFDL SCMs underestimate lower-to-middle level cloud fraction but overestimate upper-level cloud fraction. The three Community Atmosphere Model (CAM) SCMs overestimate upper-level cloud fraction and produce lower-level cloud fraction similar to the observations but as a result of compensating overproduction of convective cloud fraction and underproduction of stratiform cloud fraction. Besides, the CAM3 and CAM5 SCMs both overestimate midlevel cloud fraction, whereas the CAM4 SCM underestimates. The frequency and partitioning analyses show a large discrepancy among the seven SCMs: Contributions of nonstratiform processes to cloud fraction production are mainly in upper-level cloudy events over the cloud cover range $10 \%-80 \%$ in SCMs with prognostic cloud fraction schemes and in lower-level cloudy events over the cloud cover range $15 \%-50 \%$ in SCMs with diagnostic cloud fraction schemes. Further analysis reveals different relationships between cloud fraction and relative humidity $(\mathrm{RH})$ in the models and observations. The underestimation of lower-level cloud fraction in most SCMs is mainly due to the larger threshold RH used in models. The overestimation of upper-level cloud fraction in the three CAM SCMs and two GFDL SCMs is primarily due to the overestimation of $\mathrm{RH}$ and larger mean cloud fraction of cloudy events plus more occurrences of RH around $40 \%-80 \%$, respectively.
\end{abstract}

\section{Introduction}

Clouds are a major source of uncertainty in future climate change projections (e.g., Cess et al. 1996; Solomon et al. 2007; Boucher et al. 2014). This motivates the

\footnotetext{
* Supplemental information related to this paper is available at the Journals Online website: http://dx.doi.org/10.1175/JCLI-D-1300555.s1.

Corresponding author address: Hua Song, Atmospheric Sciences Division, Brookhaven National Laboratory, 75 Rutherford Dr., Bldg. 815E, Upton, NY 11973-5000.

E-mail: hsong@bnl.gov; lyg@bnl.gov
}

quantitative evaluations of clouds in climate models against in situ and remote sensing observational data. A key question is how to use the increasingly available observational data to efficiently evaluate the performance of climate models in representing clouds. Testing the treatment of cloud-related physical processes in full general circulation models (GCMs) is both scientifically and computationally demanding. An alternative approach is the use of single-column models (SCMs): namely, modeling the atmosphere in a single column of climate models (Randall et al. 1996).

With the collective effects of the surrounding grid columns being constrained by observations, the SCMbased approach has proven to be a powerful tool for 
evaluating parameterizations of subgrid-scale processes (i.e., Neggers et al. 2012; Zhang et al. 2013) and has been adopted by several major scientific programs, including the Global Energy and Water Cycle Experiment (GEWEX) Cloud System Study (GEWEX Cloud System Science Team 1993) and the U.S. Department of Energy's Atmospheric Radiation Measurement Program (ARM; Stokes and Schwartz 1994; Ackerman and Stokes 2003) and Atmospheric System Research (ASR) program. ARM/ASR has organized a series of SCM intercomparison studies using observations at the ARM sites. Most of these studies are focused on specific cases over a week- or month-long periods (e.g., Ghan et al. 2000; Xie et al. 2002, 2005; Xu et al. 2005; Klein et al. 2009; Morrison et al. 2009; Davies et al. 2013). However, to make a statistically meaningful comparison and evaluation of model performance, longer SCM simulations are desirable. To carry out long-term SCM simulations, one must obtain the reliable long-term large-scale advective tendency (forcing) data. ARM has constructed the multiyear continuous large-scale forcing data over the ARM Southern Great Plains (SGP) site, using an objective variational analysis method and constrained by the surface and top-of-theatmosphere observations (Xie et al. 2004). Forced with these continuous forcing data, several-year-long SCM simulations of the Goddard Institute for Space Studies (GISS) model at the ARM SGP site have been used to analyze cloud feedbacks by Del Genio et al. (2005) and to evaluate the model performance on cloud simulations by Kennedy et al. (2010). Using these observationally constrained continuous large-scale forcing data, we have carried out 3-yr (1999-2001) simulations of seven GCMs participating in the Fast-Physics System Testbed and Research (FASTER) project at the ARM SGP site, with the aid of the FASTER SCM test bed. Detailed information on the FASTER project and the test bed can be found online (at http://www.bnl.gov/ faster/). In our previous study (Song et al. 2013), evaluation of precipitation in the 3-yr SCM simulations using the ARM observations shows that, although the seven SCMs can produce the observed precipitation reasonably well, they differ tremendously in details and suffer from compensating errors between precipitation intensity and frequency. The different SCM performances and associations with large-scale forcing and thermodynamic factors shed useful insights on convection parameterizations and future development. To further expose the parameterization deficiencies, this paper focuses on evaluation of cloud fraction.

Accurate simulation of the vertical structure of cloud fraction in a model is critical to understand cloud feedback processes. The vertical distribution of clouds may affect the vertical heating profiles through radiative and latent heating processes and thus influence the atmospheric stratification and general circulation (e.g., Stephens et al. 2002). Qian et al. (2012) evaluated the cloud fraction simulated in the Intergovernmental Panel on Climate Change (IPCC) Fourth Assessment Report (AR4) GCMs at three ARM sites, demonstrating the significant differences in the model performances of cloud simulation at different vertical levels and different sites. Kennedy et al. (2010) showed that the simulated clouds at different levels in the GISS SCM are differently biased from the surface and satellite observations and also revealed the different dependences of the modeled high and low clouds on the large-scale synoptic patterns and variables.

This study evaluates some key features (vertical profiles, amounts, and frequencies) of cloud fraction simulated by seven SCMs against the ARM observations at the SGP site. We first examine the seasonal and diurnal variations of cloud fraction and illustrate the striking differences in the vertical structures of cloud fraction between the SCMs and observations and among the SCMs. We then analyze the possible factors that could contribute to these differences through partitioning the nonstratiform and stratiform cloudy events in the seven SCMs. Last, we investigate the possible influences of relative humidity on the model biases of cloud fraction in connection with model parameterizations. The rest of the paper is organized as follows: Section 2 describes the models and data used in this study. The main results are presented in sections 3-6. Section 7 summarizes the major conclusions.

\section{Model description and evaluation data}

\section{a. Participating models}

Three main U.S. GCMs [the Community Atmosphere Model (CAM), the Geophysical Fluid Dynamics Laboratory (GFDL) Atmospheric Model (AM), and the Goddard Institute for Space Studies (GISS) Model E2] and one European GCM [the European Centre for Medium-Range Weather Forecasts (ECMWF) Integrated Forecast System (IFS)] participate in the FASTER project. To further enhance the diagnosis of parameterizations and track the model improvement, the CAM and GFDL AM also include multiple versions (CAM3, CAM4, and CAM5; AM2 and AM3). Note that the GFDL AM3 used here is not the full version of GFDL AM3 (Donner et al. 2011). Here, the major change of the AM3 from the AM2 is the convection scheme. The AM2 uses the relaxed Arakawa-Shubert scheme (Moorthi and Suarez 1992) for both deep and shallow convections while the AM3 uses the Donner 
cumulus scheme (Donner et al. 2001, 2011) for deep convection and University of Washington (UW) scheme (Bretherton et al. 2004) for shallow convection. Table 1 summaries the seven GCMs used in the intercomparison study, including the number of vertical layers, time steps, cloudiness parameterization schemes, and key corresponding references.

The models determine cloud fraction in various ways. The ECMWF IFS, GFDL AM2, and GFDL AM3 use prognostic cloud fraction schemes based on Tiedtke (1993) with different modifications. Major modifications in the ECMWF IFS involve the treatments of ice fallout (Gregory et al. 2000) and ice supersaturation (Tompkins et al. 2007), whereas the GFDL AMs involve the treatment of supersaturated conditions in grid cells and the erosion constant (Anderson et al. 2004). The production of cloud fraction is determined by advection terms, source terms from convection and stratiform condensation processes, and the sink term from evaporation. The GISS Model E2 and three CAMs use different diagnostic cloud fraction schemes. The diagnostic schemes partition cloud fraction into two types of clouds: convective and stratiform. In the GISS Model E2, the convective cloud fraction is determined by updraft mass flux and convective updraft speed, and the stratiform cloud fraction is a joint function of convective stability and relative humidity $(\mathrm{RH})$ with a threshold $\mathrm{RH}$, which varies with the environmental state (Naud et al. 2010). In the three CAMs, the convective cloud fraction is determined by updraft mass flux (Xu and Krueger 1991), and the stratiform cloud fraction is determined by $\mathrm{RH}$ with a threshold $\mathrm{RH}$, which varies with atmospheric pressure. The stratiform cloud fraction is only above zero when RH exceeds the threshold RH. The CAM3 and CAM4 additionally diagnose the low-level marine stratus using an empirical relationship between cloud fraction and the lower-tropospheric stability, which is defined as the difference in potential temperature between the surface and $700 \mathrm{hPa}$ (Klein and Hartmann 1993). In the CAM5, ice cloud fraction is diagnosed separately from liquid cloud fraction (Gettelman et al. 2010). Total cloud fraction is the sum of stratiform cloud fraction and convective cloud fraction in the GISS Model E2 and CAM5, while it is the maximum of stratiform cloud fraction and convective cloud fraction in the CAM3 and CAM4. The major difference between cloud fraction schemes in the CAM3 and CAM4 is that the CAM4 employs a modification to stratiform cloud fraction by reducing the diagnosed low cloud fraction if grid mean water vapor is less than a threshold (Vavrus and Waliser 2008). This modification vastly reduces the frequency of "empty clouds" seen in the CAM3, where cloud condensate was zero and yet cloud fraction was nonzero because of an inconsistency between microphysical and macrophysical schemes. Details of these cloud fraction schemes can be found in the references given in Table 1.

To drive the SCM simulation, both the large-scale horizontal and vertical advective tendency, along with surface heat fluxes, are prescribed using the ARM variational analysis product (Xie et al. 2004), which is generated by constraining the National Oceanic and Atmospheric Administration Rapid Update Cycle, version 2 (RUC-2) analyses with ARM surface and topof-the-atmosphere (TOA) satellite measurements. This RUC-based continuous forcing dataset has the advantage of being available for driving SCMs over long periods, with a quality often comparable to that from intensive observing periods (IOPs) (Xie et al. 2004; Del Genio et al. 2005; Kennedy et al. 2010).

For the 3-yr simulations from January 1999 to December 2001, all seven SCMs are reinitialized at the beginning of each month and integrated for the whole month. The relaxation of temperature and specific humidity is employed at each time step to keep modeled temperature and moisture from drifting in the long-term integration (Randall and Cripe 1999; Henderson and Pincus 2009). The SCM outputs are averaged over $1 \mathrm{~h}$ and vertically interpolated to 20 pressure vertical levels (50-1000 hPa with an interval of $50 \mathrm{hPa}$ ). Detailed information about the model configuration and setup can be found in Song et al. (2013).

\section{b. Evaluation data}

The evaluation dataset used in this study is the active remotely sensed cloud layers (ARSCL) cloud fraction provided by the ARM Best Estimate (ARMBE) products (Xie et al. 2010). The ARMBE data products aim to transforming detailed ARM observations into a form that can be easily used by the climate modeling community for model evaluation and development. The ARMBE ARSCL cloud fraction is based on the ARSCL cloud boundary information and derived from the ARSCL cloud information. The ARSCL product provides estimates of total amount and vertical locations of clouds (Clothiaux et al. 1999, 2000). The high vertical resolution of the ARSCL cloud fraction is particularly valuable in identification of model deficiencies. Note that the ARSCL cloud fraction, derived from upwardlooking narrow view radar-lidar pair of measurements, actually represents the frequency of cloud occurrence within a specified sampling time period rather than fractional cloud area coverage as defined in models. However, previous studies (e.g., Dong et al. 2006; Xie et al. 2010; Kennedy et al. 2010; Qian et al. 2012) have found that the long-term averaged ARSCL cloud 
1 SEPTEMBER 2014

SONG ET AL.

6701

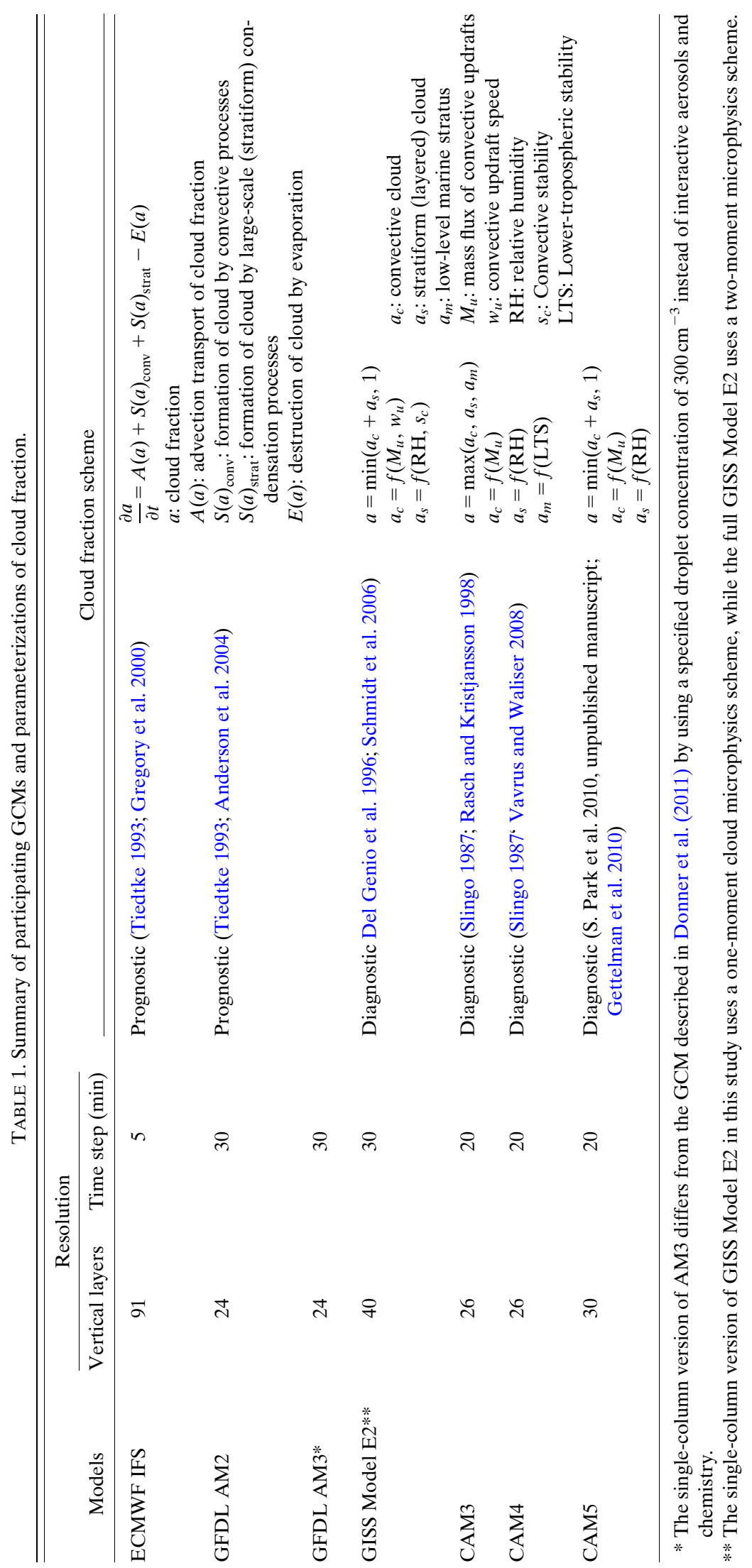

Unauthenticated | Downloaded 04/26/23 11:11 AM UTC 
occurrence can represent large areal cloud fraction observations, which provides confidence for using the ARSCL multiyear cloud fraction to statistically evaluate the simulated cloud fraction.

The ARMBE products also provide vertical profiles of RH measured by balloon-borne soundings up to four times daily at the ARM SGP Central Facility. The sounding RH data have a known dry bias (Turner et al. 2003), but the ARMBE uses the Microwave RadiometerScaled Sonde Profiles (LSSONDE) value-added product (VAP) to remove this bias (Turner et al. 1998; Xie et al. 2010). However, the sounding RH data are very sparse in the years 1999-2001. There are only about $2400 \mathrm{~h}$ (about $300 \mathrm{~h}$ at levels below $950 \mathrm{hPa}$ and above $150 \mathrm{hPa}$ ) with valid sounding $\mathrm{RH}$, much less than the $25000 \mathrm{~h}$ of valid ARSCL cloud fraction and RUC-based RH in the continuous forcing dataset (Xie et al. 2004). Large differences between the RUC-based $\mathrm{RH}$ and sounding $\mathrm{RH}$ are shown to be mainly above 200-hPa level (Kennedy et al. 2011), where most sounding RH values are concentrated at low $\mathrm{RH}$ ranges $(\mathrm{RH}<5 \%$ ) (Figs. $\mathrm{S} 1$ and $\mathrm{S} 2$ in the supplementary material). Minnis et al. (2005) revealed that the large differences between sounding $\mathrm{RH}$ and RUC-based RH at high levels mainly occur in clear and cloud-free conditions. In our simulations, we use the RUC-based temperature and specific humidity from the continuous forcing dataset to derive the relaxation terms for temperature and specific humidity at each time step. Considering all these factors, the RUC-based RH from the continuous large-scale forcing dataset is used to evaluate modeled RH as well.

The surface precipitation observational data used in our analysis are the hourly Arkansas-Red Basin River Forecast Center (ABRFC) 4-km rain gauge adjusted Weather Surveillance Radar-1988 Doppler (WSR-88D) measurements averaged over the variational analysis domain (Xie et al. 2004).

\section{Seasonal, diurnal, and vertical variations of cloud fraction}

The 3-yr average seasonal variations of cloud fraction profile in the observations and seven SCMs are shown in Fig. 1. The seasonal variations of the observed cloud fraction exhibit a bimodal vertical distribution with a higher peak at 400-200 hPa from January to July and a lower peak around $850 \mathrm{hPa}$ from March to June. The largest cloud fraction occurs from winter to spring, when baroclinic wave activities are common over the SGP site. The minimum cloud fraction occurs during summer. The three SCMs with prognostic cloud fraction schemes (ECMWF IFS, GFDL AM2, and GFDL AM3) well produce the seasonal variation pattern in the observations (shading in Figs. 1b-d). For the other four SCMs with diagnostic cloud fraction schemes, the GISS SCM captures the observed cloud fraction peaks in the cold season (November-April) and cloud fraction minima in the warm season (May-October), but all three CAM SCMs have difficulty in capturing the observed seasonal phases and generally have a weak seasonal contrast especially at lower levels (shading in Figs. 1e-h).

Contours in Fig. 1 show the seasonal variations of cloud fraction differences between the seven SCMs and observations. Compared with the observations, the ECMWF SCM underestimates almost all clouds throughout the year. The two GFDL SCMs underestimate low-level clouds and overestimate high-level clouds in all months. The GISS SCM underestimates clouds at most levels in each month and mildly overestimates upper-level clouds above $300 \mathrm{hPa}$ from October to April and lower-level clouds between 600 and $800 \mathrm{hPa}$ in July and August. For the three versions of CAM SCMs (SCAMs: SCAM3, SCAM4, and SCAM5), there are some similarities and differences. The SCAM4 has a similar bias pattern as the SCAM3 but with smaller biases from May to November, except for clouds around $200 \mathrm{hPa}$ and clouds below $800 \mathrm{hPa}$ from April to July. The SCAM3 and SCAM5 strongly overestimate upper-level cloud fraction between 350 and $200 \mathrm{hPa}$, especially around May. Besides, the SCAM5 has more near-surface low-level clouds than the observations and other SCMs. One noteworthy point is that, different from all the other SCMs, all three SCAMs mildly overestimate lower-level cloud fraction during the warm season. This feature is most likely a result of a daytime bias in lower-level clouds in this season (not shown). Here, daytime is defined as solar insolation at TOA being larger than $0.01 \mathrm{~W} \mathrm{~m}^{-2}$ (otherwise nighttime).

The striking phenomenon that only the three SCAMs overestimate lower-level cloud fraction during warm season deserves further inspection. Clouds in the three SCAMs are composed of two types: convective and stratiform, which are separately diagnosed and outputted at each integration time step. Figure 2 shows the differences in monthly-mean daytime cloud fractions between the convective clouds in the SCAMs and the total clouds in the observations and that between the stratiform clouds in the SCAMs and the total observed. It is striking that the convective cloud fractions from the SCAMs alone are already much larger than the observed total cloud fraction in most months and at most levels, whereas the stratiform clouds alone would have caused the underestimation of lower-level cloud fraction (except below $850 \mathrm{hPa}$ for the SCAM5) and the overestimation of highlevel cloud fraction in most months in the three SCAMs. These results imply that the overestimation of warmseason lower-level clouds in the three SCAMs is mainly 

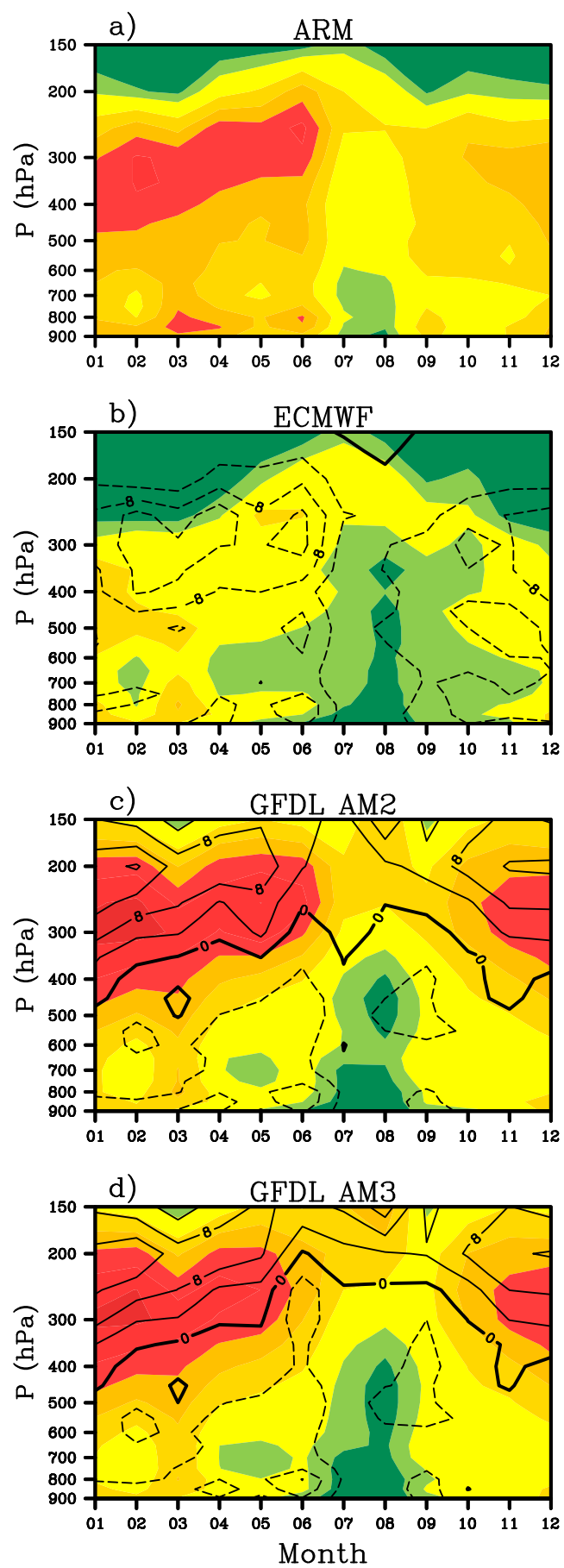


Cloud Fraction (\%)

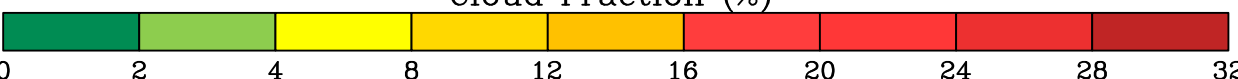

FIG. 1. Seasonal variations of 3-yr monthly-mean cloud fraction in the (a) ARM observations and (b)-(h) seven SCMs (shading) and model-observation differences in seasonal variations (contours). The contour interval is $4 \%$.

due to too many convective clouds that are diagnosed from the convective mass flux. The excessive convective cloud fraction in SCAMs is mainly due to their overactive convection, which is easily triggered during the daytime
(Xie et al. 2002). It is also noteworthy that, during the three years, events with nonzero convective cloud fraction mainly occur during warm-season daytime at lower-tomiddle levels (Fig. 2, bottom), which leads to the negligible 

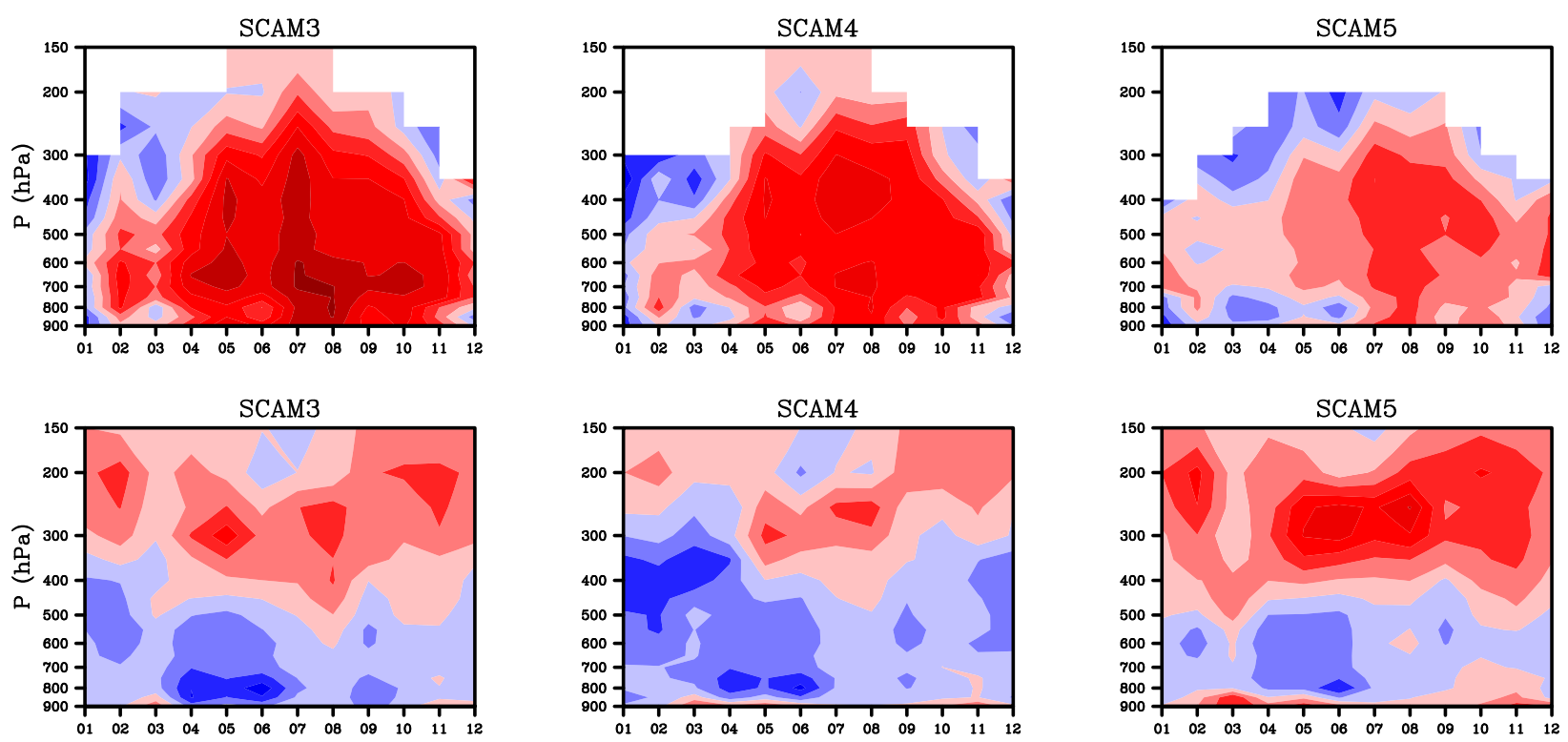

Difference in Cloud Fraction (\%)

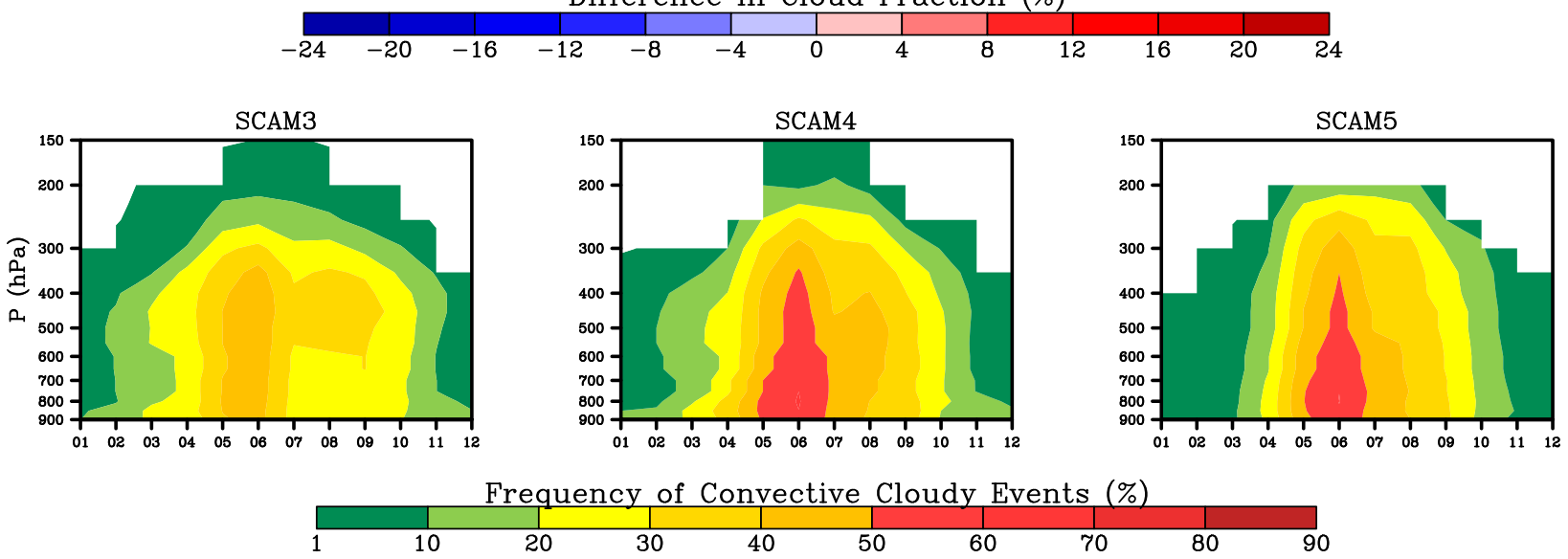

FIG. 2. Daytime monthly-mean difference (top) between SCAM conditional convective cloud fraction (i.e., cloud fraction averaged only over times when convective cloudy events occurs) and ARSCL cloud fraction and (middle) between SCAM conditional stratiform cloud fraction and ARSCL cloud fraction. (bottom) Occurrence frequency of daytime convective cloudy events in the three SCAMs.

contribution of convective cloud fraction to the model biases in upper-level total cloud fraction.

Figure 3 demonstrates the diurnal variations of the warm-season (May-October) cloud fraction in the observations and the seven SCMs. The observations show clear diurnal variations in the warm season, with a primary peak of cloud fraction around $250 \mathrm{hPa}$ during the nighttime and a second peak during the morning at low levels. Only the GFDL SCMs produce a diurnal variation close to the observations in terms of the diurnal phase. The ECMWF SCM captures the observed diurnal phase at levels below $500 \mathrm{hPa}$ but produces the wrong diurnal phase at high levels. The GISS SCM produces a similar diurnal phase as the observations at the upper levels above $400 \mathrm{hPa}$, but the peak at the lower levels is shifted to earlier hours in the night. The diurnal phases in the three SCAMs differ much more from the observations. The diurnal phases are just the opposite at the low levels compared to the observations, while at upper levels the peak cloud coverage occurs much earlier in the afternoon. In the cold season (November-April), the diurnal variations of cloud fraction in the observations and the seven SCMs all show weak diurnal variations (not shown).

The above analyses demonstrate that the modelobservation differences in cloud fraction are so persistent that the signs of the biases mostly last throughout the year and across the hours of the day, with the exception that the convection-induced lower-to-middle level positive biases in the SCAMs stand out during the daytime of the 
a)

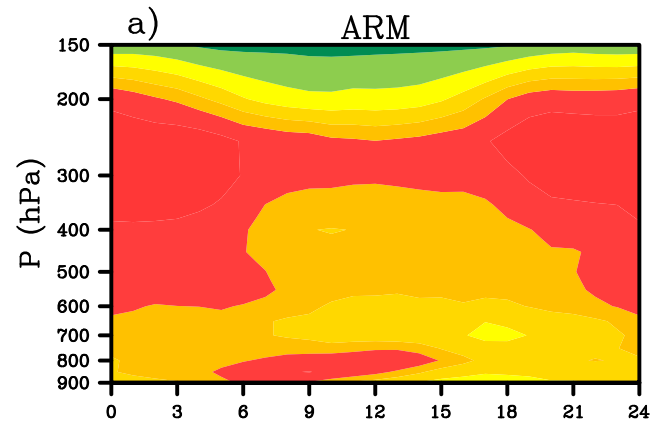

b)

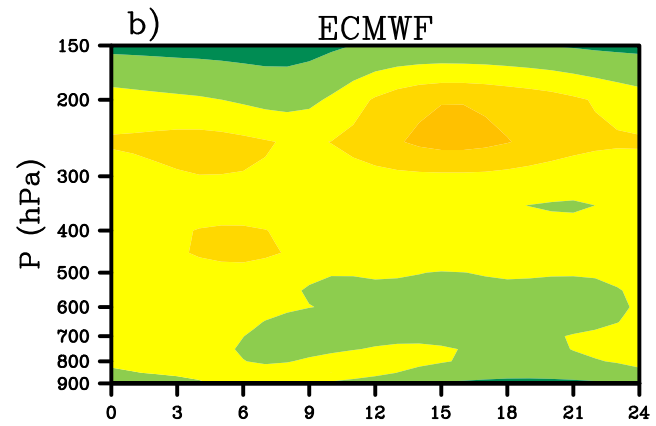

c)

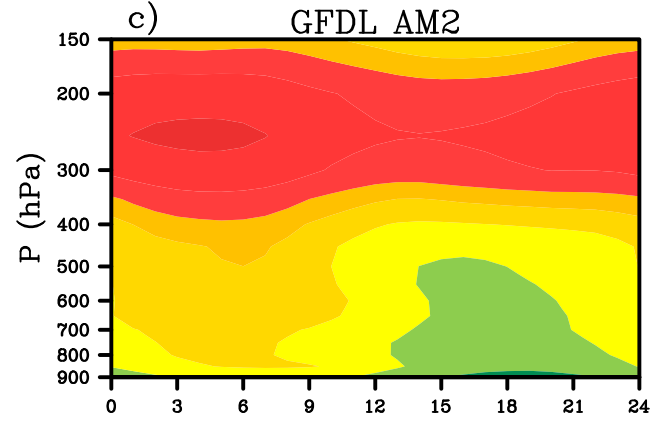

d)

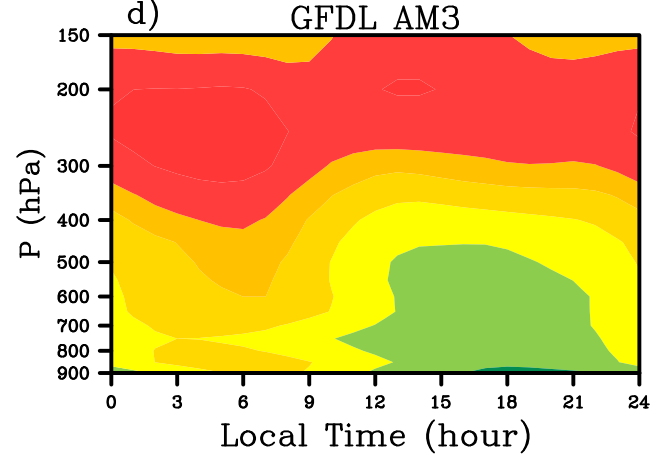

e)
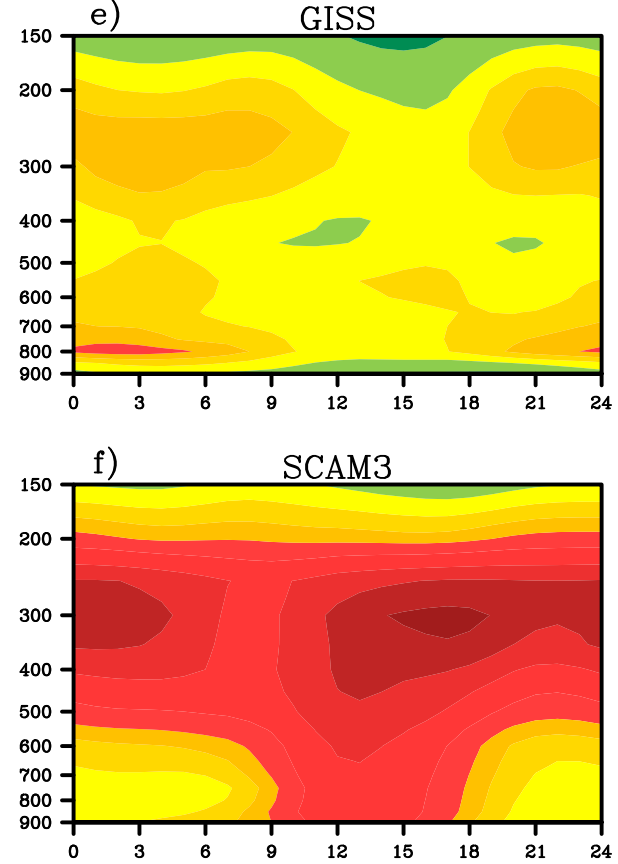

g)

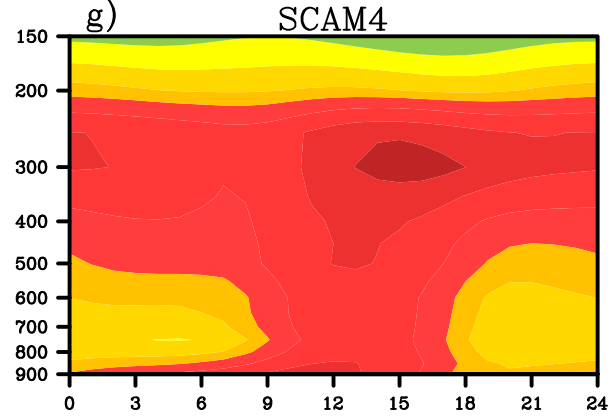

h)

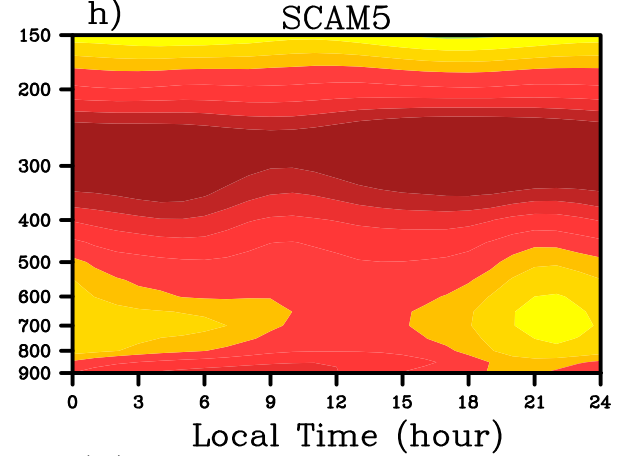

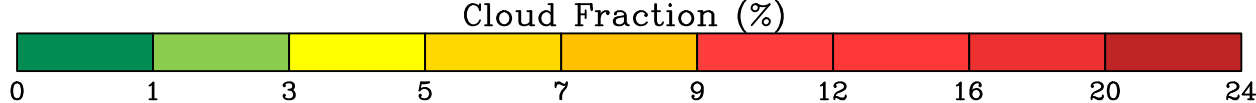

FIG. 3. Diurnal variations of 3-yr cloud fraction in (a) ARM observations and (b)-(h) seven SCMs in warm season (May-October). SGP local time $=\mathrm{UTC}-6 \mathrm{~h}$. Contour intervals are $2 \%$ for negative values and $4 \%$ for positive values.

warm season. Figure 4 shows the vertical profiles of 3-yr mean cloud fraction in the observations and SCMs. As expected from what are shown previously, the ECMWF SCM significantly underestimates all clouds. The GISS
SCM underestimates all clouds below $200 \mathrm{hPa}$. The two GFDL SCMs overestimate upper-level clouds and underestimate lower-to-middle level clouds. The three SCAMs overestimate upper-level clouds but have 
a lower-level (800-600 $\mathrm{hPa}$ ) cloud fraction similar to the observations. However, a further inspection reveals that the apparent agreement between the three SCAMs and observations stems from the compensating overproduction of convective cloud fraction during the daytime of the warm season and a general underproduction of stratiform cloud fraction. The SCAM3 and SCAM5 both overestimate midlevel cloud fraction while the SCAM4 underestimates. Besides, the SCAM5 has more near-surface low-level clouds than the observations and other SCMs. In short, compared with the observations, most SCMs overestimate upper-level cloud fraction and underestimate lower-level cloud fraction but still with some differences in details. Note that here we loosely define clouds above $350 \mathrm{hPa}$ as the upper-level clouds and clouds below $600 \mathrm{hPa}$ as lower-level clouds to more concisely characterize the discrepancies between the observation and simulated cloud fraction from all the seven SCMs. This partition is different from the conventional definition (e.g., Hahn et al. 2001).

One source of errors in the cloud radar observations is the attenuation during heavy precipitation events; the radar tends to underestimate upper-level clouds when precipitation is strong and the cloud is deep ( $\mathrm{Wu}$ et al. 2009; Lin et al. 2012). To minimize the possible influence of precipitation on the accuracy of the ARSCL cloud fraction and thus the evaluation of modeled cloud fraction against the observations, we excluded events with observed surface precipitation rate larger than $40 \mathrm{~mm} \mathrm{day}^{-1}$ in the following analyses. The model-observation cloud fraction differences appear to have little dependence on the observed precipitation rate when the observed precipitation rate is smaller than $40 \mathrm{~mm} \mathrm{day}^{-1}$ (Fig. S3 in the supplementary material). The total occurrence frequency of heavy precipitation events $\left(\operatorname{Pr}>40 \mathrm{~mm} \mathrm{day}^{-1}\right)$ is only $1.4 \%$ in the years from 1999 to 2001, and the vertical profiles of 3-yr mean cloud fraction in the observations and the seven SCMs after the exclusion of observed heavy precipitation events are nearly identical to those in Fig. 4. In the following sections, we investigate why the seven SCMs have such striking biases in cloud fraction at different levels.

\section{Partitioning analysis of cloud fraction}

The preceding analysis shows that there are not only significant differences between the SCMs and observations but also substantial intermodel discrepancies in the simulated cloud fraction. The intermodel differences can be due to their different stratiform and convective cloud parameterizations. To identify the specific sources, this section aims to partition the influences of these two main types on the modeled cloud fraction.

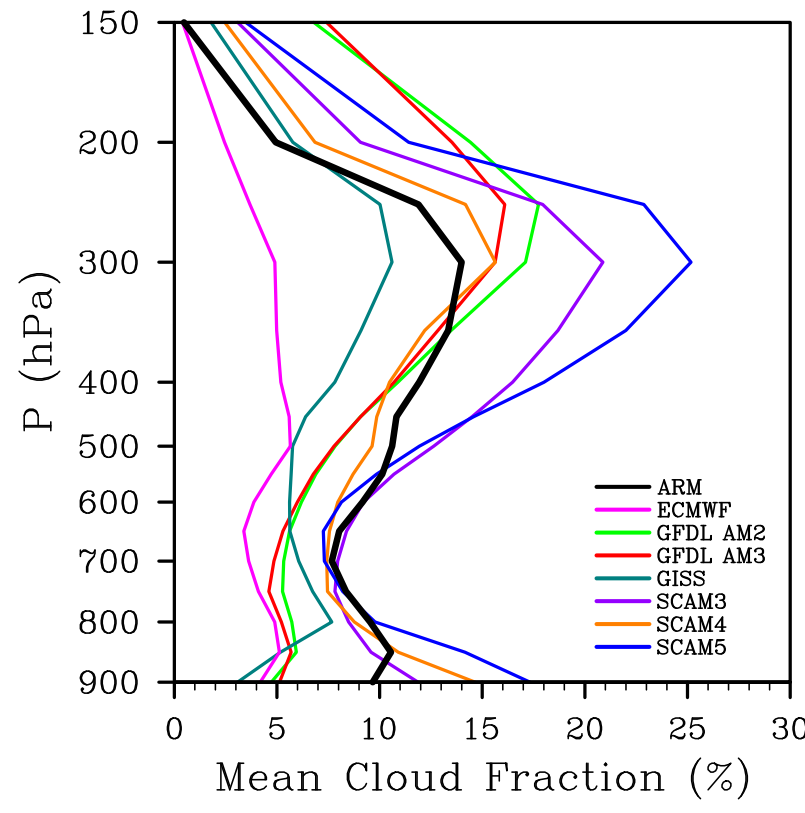

FIG. 4. Vertical profiles of 3-yr mean cloud fraction in ARM observations and seven SCMs.

In the diagnostic cloud fraction schemes of the GISS Model E2 and three CAMs, the convective cloud fraction and stratiform cloud fraction are calculated separately. The convective cloud fraction is related to updraft mass fluxes in the deep and shallow cumulus schemes and the stratiform cloud fraction is a function of $\mathrm{RH}$ and the threshold RH. In the prognostic cloud fraction schemes of the ECMWF and two GFDL GCMs, the convection source term is proportional to the mass detrainment of cumulus updrafts. The source term of the stratiform process is a function of $\mathrm{RH}$ and only produces cloud fraction when $\mathrm{RH}$ exceeds a threshold $\mathrm{RH}$. The evaporation term is also a function of RH. The stratiform source term and evaporation sink term can be considered together as the RH-related terms. Different from the GISS and CAM models, the ECMWF and GFDL models do not explicitly provide the contributions of stratiform source and convective source to total cloud production. For consistency, a procedure commonly applicable to all the models is proposed and described below that partitions cloud fraction into the stratiform and nonstratiform (primarily convective) cloud sources.

Because the detrainment rate and mass flux of deep/ shallow cumulus updrafts are not standard outputs of most GCMs and were not saved for this study, we use convective precipitation rate to indirectly represent convection-related processes and define convective events as the events whereby the modeled convective precipitation rate is larger than $0.1 \mathrm{~mm} \mathrm{day}^{-1}$. To further 
exclude the events with stratiform cloud production in models during convective precipitation processes, we also add an additional constraint of $\mathrm{RH}<80 \%$ based on the fact that thresholds of $\mathrm{RH}$ in the stratiform source term in both prognostic and diagnostic schemes are normally around $80 \%$ (from $60 \%$ to $90 \%$ ) in most models. Note that the variable threshold RH in the GISS model is about $60 \%$ on average; the analyses using RH $<80 \%$ or $<60 \%$ do not show any significant difference for the GISS SCM.

For the ECMWF and GFDL SCMs using the prognostic cloud fraction scheme, cloud fraction is locally produced by the competition of the large-scale vertical transport of cloud fraction, convection and/or largescale condensation processes, and evaporation, since the continuous large-scale forcing data (Xie et al. 2004) do not provide any large-scale hydrometeor advection. Without horizontal advection of cloud fraction, clouds cannot be removed from or added into the grid box by surrounding dynamical fluxes. As a result, cloud fraction in the next time step will keep on accumulating the model bias at the previous time steps if there is no strong source or sink of cloud fraction (hence small time tendency of cloud fraction). Under such conditions, the model cloud bias is not necessarily a flawed response of model physics to the large-scale environment. To illustrate the influence of accumulated model bias in cloud fraction on the following time step with weak time tendency of cloud fraction, we also pick out the events that have a small absolute value of modeled cloud fraction tendency (much smaller than the cloud fraction bias at the previous time step), convective precipitation rate smaller than $0.1 \mathrm{~mm} \mathrm{day}^{-1}$, and $\mathrm{RH}$ smaller than $80 \%$. These events are neither purely convection nor purely stratiform sources, and are included in the type of nonstratiform-source events.

By use of the above partition procedure, modeled cloudy events are separated into two types: nonstratiform-source events (with convection sources or small time tendency of cloud fraction for the ECMWF and two GFDL SCMs) and stratiform-source events. The detailed criteria for the partitioning analysis are listed in Table 2. It should be emphasized that this partitioning method is tailored only for modeled cloud fraction. In the real atmosphere the convective detrainment can produce stratiform anvils, whereas in models these anvils may be calculated from RH (when RH exceeds a threshold), instead of by the convective scheme (e.g., in SCAMs). Therefore, here we assume these anvil clouds in models to be produced by the stratiform sources rather than the convective sources (e.g., when convective precipitation occurs and $\mathrm{RH}>80 \%$ ).

The 3-yr mean cloud fraction at each level can be partitioned into the mean cloud fractions of the events with nonstratiform sources and of the events with stratiform sources, respectively,

$$
\overline{\mathrm{CF}}=\frac{\sum_{i=0}^{i=N_{\text {tot }}} \mathrm{CF}_{i}}{N_{\text {tot }}}=\frac{\sum_{i=0}^{i=N_{1}} \mathrm{CF}_{i} \mid E_{1}}{N_{\text {tot }}}+\frac{\sum_{i=0}^{i=N_{2}} \mathrm{CF}_{i} \mid E_{2}}{N_{\text {tot }}}+\frac{\sum_{i=0}^{i=N_{3}} \mathrm{CF}_{i} \mid E_{3}}{N_{\text {tot }}}=\overline{\mathrm{CF}}_{\text {non-strat }}+\overline{\mathrm{CF}}_{\text {strat }}+\overline{\mathrm{CF}}_{\text {both }},
$$

where CF stands for cloud fraction at any vertical level; $N_{\text {tot }}=25852$, which is the total number of time points in the 3-yr hourly data; $E_{1}$ represents nonstratiformsource events; $N_{1}$ is total number of time points with nonstratiform-source events; $E_{2}$ represents stratiformsource events; $N_{2}$ is total number of time points with stratiform-source events; $E_{3}$ represents events with comparable nonstratiform source and stratiform source; $N_{3}$ is total number of time points with such events; $N_{\text {tot }}=$ $N_{1}+N_{2}+N_{3} ; \overline{\mathrm{CF}}$ represents the 3 -yr mean cloud fraction averaged for all events; $\overline{\mathrm{CF}}_{\text {non-strat }}$ represents the contribution of the nonstratiform-source events to the 3-yr mean cloud fraction; $\overline{\mathrm{CF}}_{\text {strat }}$ represents the contribution of the stratiform-source events; and $\overline{\mathrm{CF}}_{\text {both }}$ represents the contribution of the events with comparable nonstratiform source and stratiform source. Note that, in the following analyses, we have not separately considered the events with comparable nonstratiform source and stratiform source because the contributions of these events are very small in all SCMs. Instead we include these events in the stratiform-source events.

The vertical profiles of 3-yr mean cloud fractions for nonstratiform-source events and stratiform-source events are illustrated in Fig. 5. It is seen that the contribution of the nonstratiform-source events to the 3-yr mean cloud fraction (Fig. 4) is mainly above the 600-hPa level in the ECMWF and two GFDL SCMs and below the 400-hPa level in three SCAMs. In the GISS SCM, the mean cloud fraction of nonstratiform-source events is negligible and less than $1 \%$ at all levels. Comparing Fig. 5 with Fig. 4, the overestimation of upper-level cloud fraction in the three SCAMs can be clearly traced to the stratiform source, while the overestimation of upper-level clouds in the GFDL SCMs may be due to both stratiform and 
TABLE 2. Criteria used in the partitioning analysis. Stratiform-source events are all events excluding nonstratiform-source events. Note that events with comparable nonstratiform source and stratiform source are not separately considered and are included in the stratiformsource events.

\begin{tabular}{ll}
\hline \hline \multicolumn{1}{c}{ Models } & Nonstratiform-source events at each time step $t$ and vertical level $p$ \\
\hline ECMWF IFS & $\operatorname{Pr}_{\text {conv }}(t)>0.1$ mm day $^{-1}$ and \\
GH $(t, p)<80 \% ; \quad$ or
\end{tabular}

nonstratiform sources. Similarly, the underestimation of lower-level cloud fraction in the ECMWF SCM, two GFDL SCMs, and GISS SCM may be due to lack of cloud production by either or both the stratiform and nonstratiform sources. Furthermore, the contribution of stratiform-source events is much larger than that of nonstratiform-source events at all levels in the troposphere (below $200 \mathrm{hPa}$ ) in all seven SCMs, indicating the importance of stratiform (RH dependent) processes in producing cloud fraction during the three years (Fig. 4).

\section{Frequency distribution of cloud fraction in the seven SCMs}

Next we investigate the model performances over different cloud amount regimes. First we sort all the 3-yr

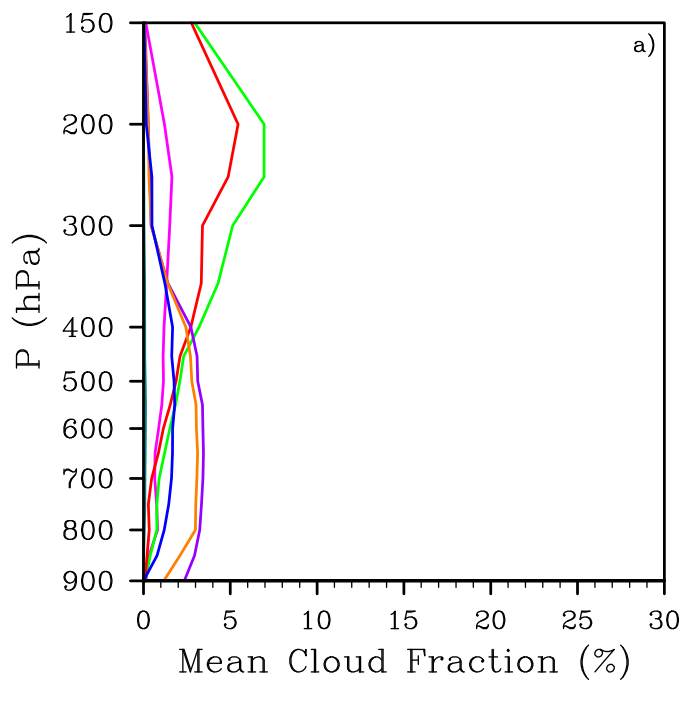

hourly cloud fraction data (total sample number is 25852 ) by their amounts (from $0 \%$ to $100 \%$ ) at each vertical level, and then we calculate the occurrence frequencies of cloud fraction at the specified ranges (each bin is $5 \%$ ). Here, frequency is the ratio of the number of events within each specified cloud fraction range to the total sample number. Figure 6 shows the frequency distributions of cloud fraction over the cloud fraction ranges from $0 \%$ to $100 \%$ at different vertical levels in the seven SCMs. The most frequent events occur with cloud fraction smaller than $10 \%$ at all levels in all SCMs. Over the cloud fraction range from $10 \%$ to $100 \%$, the frequency distributions are quite different between the models with prognostic cloud fraction schemes and those with diagnostic cloud fraction schemes. Compared with the other SCMs, the ECMWF SCM has much fewer occurrences of events with cloud

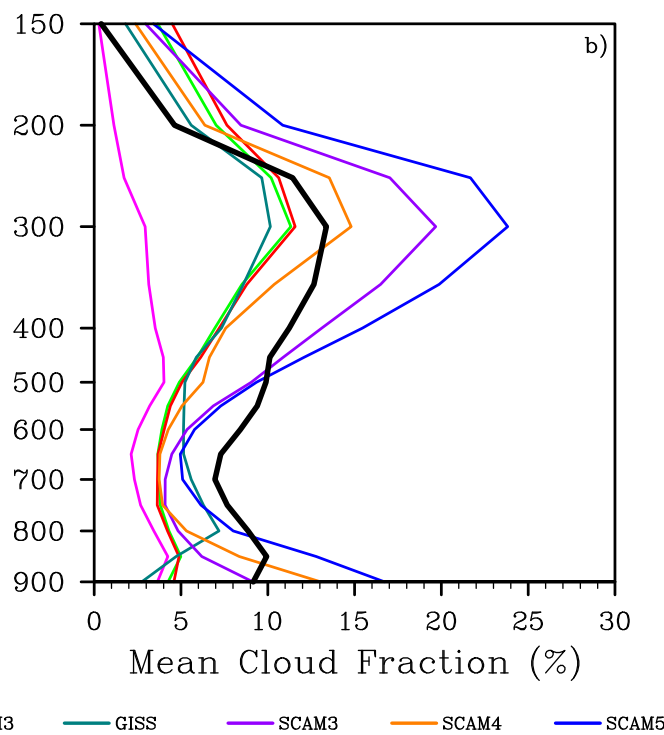

FIG. 5. (a) Vertical profiles of 3-yr mean cloud fraction in the seven SCMs for nonstratiform-source events. (b) Vertical profiles of 3-yr mean cloud fraction in the ARM observations for all events and in the seven SCMs for stratiform-source events. Events with observed surface precipitation rate larger than $40 \mathrm{~mm} \mathrm{day}^{-1}$ are excluded. 


\section{Freuquency (\%)}

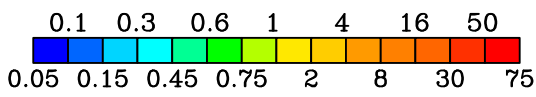
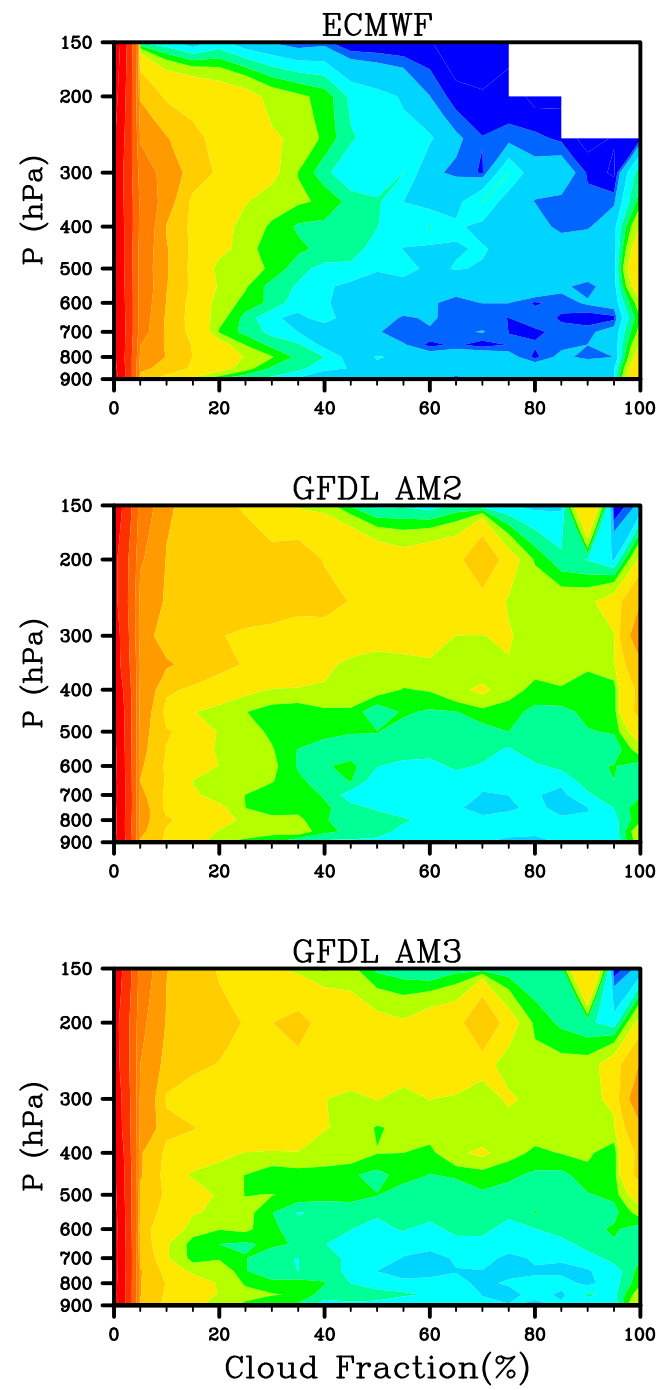
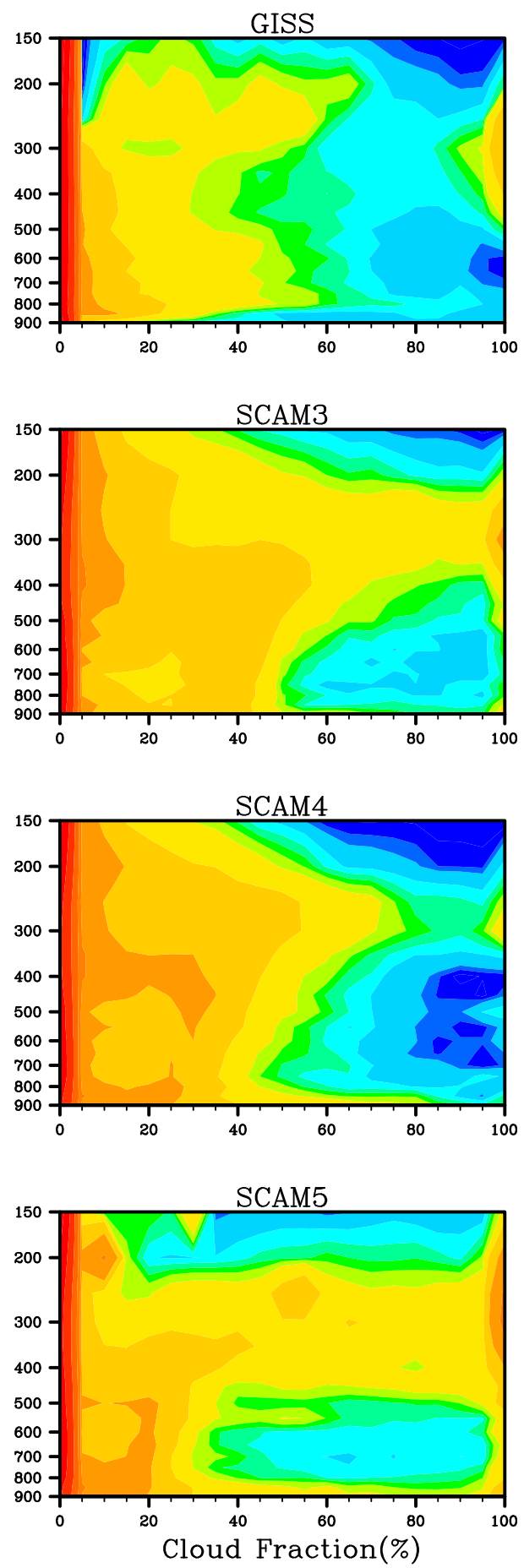

FIG. 6. Frequency distributions of cloud fraction in seven SCMs binned by cloud fraction ranging from $0 \%$ to $100 \%$. Each bin of cloud fraction is $5 \%$. Events with observed surface precipitation rate larger than $40 \mathrm{~mm} \mathrm{day}^{-1}$ are excluded.

fraction larger than $40 \%$ at all levels (except for lowlevel near-overcast events). The two GFDL SCMs have more high-level cloudy events than low-level cloudy events over the cloudy range from $20 \%$ to $100 \%$.
A special feature for the three SCAMs, different from the models with prognostic cloud schemes, is the more frequent occurrences of cloudy events over the range from $10 \%$ to $50 \%$ at all levels. Besides, among the 
three SCAMs there are large discrepancies in the frequency distributions. The SCAM4 has much fewer occurrences of extensively cloudy events than the SCAM3 and SCAM5. The SCAM5 has much more frequent near-overcast events especially at high levels than the SCAM3 and SCAM4.

Figure 7 presents the ratio of the nonstratiformsource events to all the events for each total cloud fraction bin in the seven SCMs. It is shown that, in the SCMs with prognostic cloud scheme, especially in the two GFDL SCMs, cloud fractions above the $400-\mathrm{hPa}$ level over the range $10 \%-80 \%$ are mainly produced by the nonstratiform processes (contribution of the events with small time tendency of cloud fraction is about twice as large as that of the events with convective sources), while cloud fractions below $700 \mathrm{hPa}$ are mainly produced by the stratiform processes. In the GISS SCM, the cloudy events related to convection processes are rare, which is consistent with the few convective precipitation events produced in the GISS SCM (Song et al. 2013). Because of its parcellifting-based trigger used in the convection scheme, the GISS SCM cannot convect in most events when the observation precipitation occurs (Del Genio and Wolf 2012). Our precipitation study (Song et al. 2013) shows that the mean convective precipitation rates in both the GISS and GFDL AM2 SCMs are very small but for different reasons. In the GISS SCM both the occurrence frequency and intensity of convective precipitation events are very small, whereas in the GFDL AM2 SCM the intensity of convective precipitation events is small but the occurrence frequency of convective precipitation is high and even higher than that in the GFDL AM3 SCM. This is also consistent with the overall higher ratio of nonstratiform events in the GFDL AM2 SCM than in the GFDL AM3 SCM, as can be seen in Fig. 7. For the three SCAMs, their ratios of nonstratiform events suggest that the cloud events below $400-\mathrm{hPa}$ levels over the range $15 \%-50 \%$ have a lot to do with the convective process, while the cloud fractions below the 400 -hPa level over the range $50 \%-100 \%$ and above the $300-\mathrm{hPa}$ level over the whole range are mainly produced by the stratiform process.

The diagnostic cloud fraction schemes calculate the convective and stratiform cloud fractions separately, so we can determine the relative roles of these two types of cloud source in producing the total cloud fraction. Figure 8 illustrates the ratio of convective cloud fraction to total cloud fraction averaged over each cloud fraction bin in the GISS SCM and the three SCAMs. The distributions of the ratios are generally similar to those in Fig. 7 for the GISS SCM and SCAMs. This confirms the reliability of using convective precipitation rate and $\mathrm{RH}<80 \%$ to choose the convective events for these models. In the GISS SCM, the ratio of convective cloud fraction to total cloud fraction averaged over each bin of total cloud amount is very small. The very small convective cloud fraction in the GISS SCM simulation is also reported in Kennedy (2011). In the three SCAMs, over the range from $15 \%$ to $50 \%$, clouds below the $400-\mathrm{hPa}$ level have a large contribution from convective sources. Together, the results in Figs. 6-8 suggest that the diagnostic schemes related to the convective processes in the three SCAMs produce too many clouds over this range too frequently. It is also seen in Fig. 8 that, over the range from $60 \%$ to $100 \%$, cloud fractions are mainly contributed by stratiform (nonconvective) clouds, which is diagnosed from $\mathrm{RH}$ with a threshold $\mathrm{RH}$.

\section{Cloud fraction and RH}

Many previous studies have shown the strong relationship between cloud fraction and $\mathrm{RH}$ in the observations and models (e.g., Slingo 1980; Xu and Randall 1996a,b). For stratiform cloud fraction in models, there are three ways in which $\mathrm{RH}$ could possibly influence the calculation of cloud amount: 1) values of threshold $\mathrm{RH}$ used in the cloud scheme;2) dependence of cloud fraction on RH above the threshold (viz., the diagnostic formula); and 3) modeled RH. The frequency distribution of cloudy events is mainly related to ways 1 and 3 , whereas the mean cloud amount is mainly related to ways 2 and 3 . Note that in this study, $\mathrm{RH}$ is defined with respect to liquid and/or ice depending on air temperature. Saturation mixing ratio with respect to liquid (ice) is used when temperature is above $0^{\circ} \mathrm{C}$ (below $-20^{\circ} \mathrm{C}$ ), and a linear combination with respect to liquid and ice is used between $0^{\circ}$ and $-20^{\circ} \mathrm{C}$. Next we dissect these possible influences of $\mathrm{RH}$ on the model biases in cloud fraction, revealing a close link to model parameterizations.

\section{a. Diagnosis of the threshold $R H$}

As discussed above, cloud fraction in all the seven models is related to a threshold $\mathrm{RH}$, which is specified in some models but a variable in others. Quaas (2012) proposed an approach to estimate the threshold $\mathrm{RH}$ from cloud fraction and RH in both observations and models and demonstrated that the threshold $\mathrm{RH}$ value is a powerful diagnostic for evaluating the representation of subgrid variability in cloud fraction parameterizations in GCMs. Low values of the threshold RH indicate large subgrid-scale variability of humidity. It is noteworthy that the threshold $\mathrm{RH}$ diagnosed here is a common measure for purpose of comparison, not the exact threshold RH used in the cloud fraction schemes. Briefly, assuming a uniform probability density function (PDF) of total water specific humidity $q_{t}$ in the grid box and that clouds only occur in the area where $q_{t}$ is 

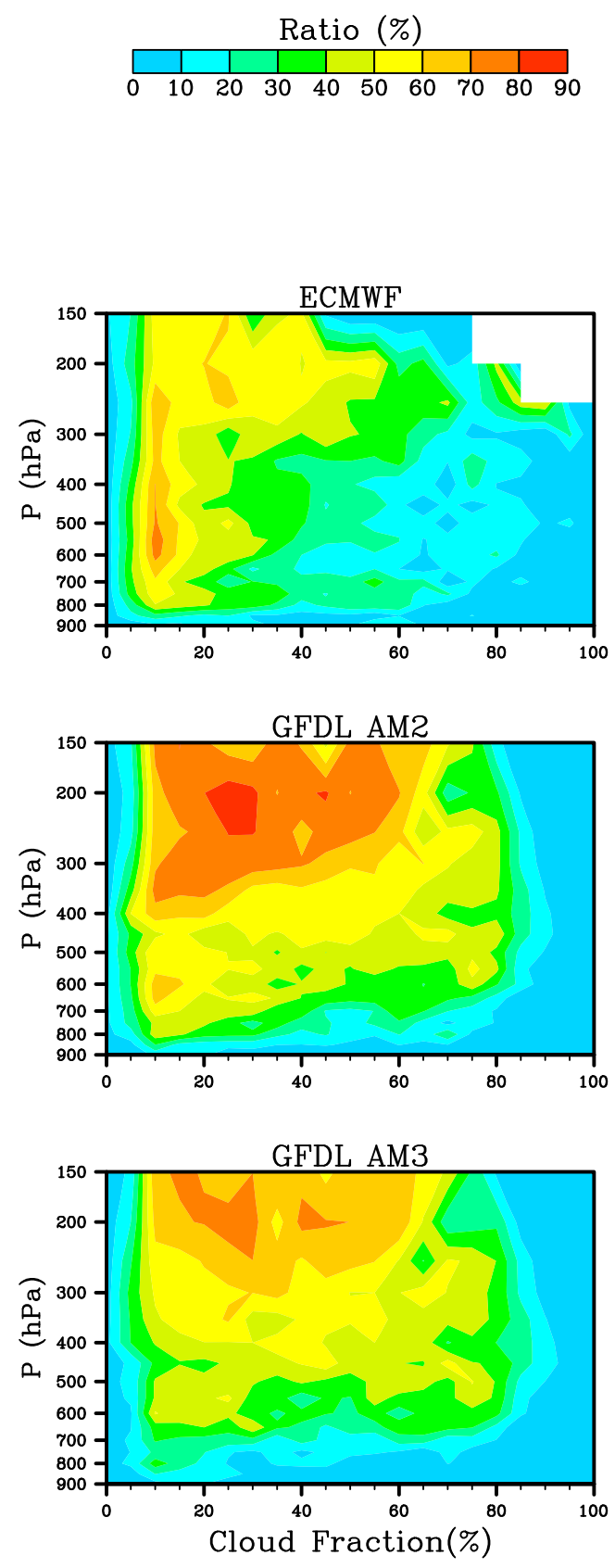

FIG. 7. Ratios of nonstratiform-source events to all the events for each total cloud fraction bins (each bin is $5 \%$ ) in the seven SCMs. Events with observed surface precipitation rate larger than $40 \mathrm{~mm} \mathrm{day}^{-1}$ are excluded.

larger than saturation specific humidity $q_{s}$, the uniform PDF with a width related to $q_{s}$ can be formulated in terms of threshold $\mathrm{RH} r_{c}$, and then cloud fraction $f$ can be expressed in terms of the gridbox mean $\mathrm{RH} \bar{r}$ and $r_{c}$ (Sundqvist et al. 1989),
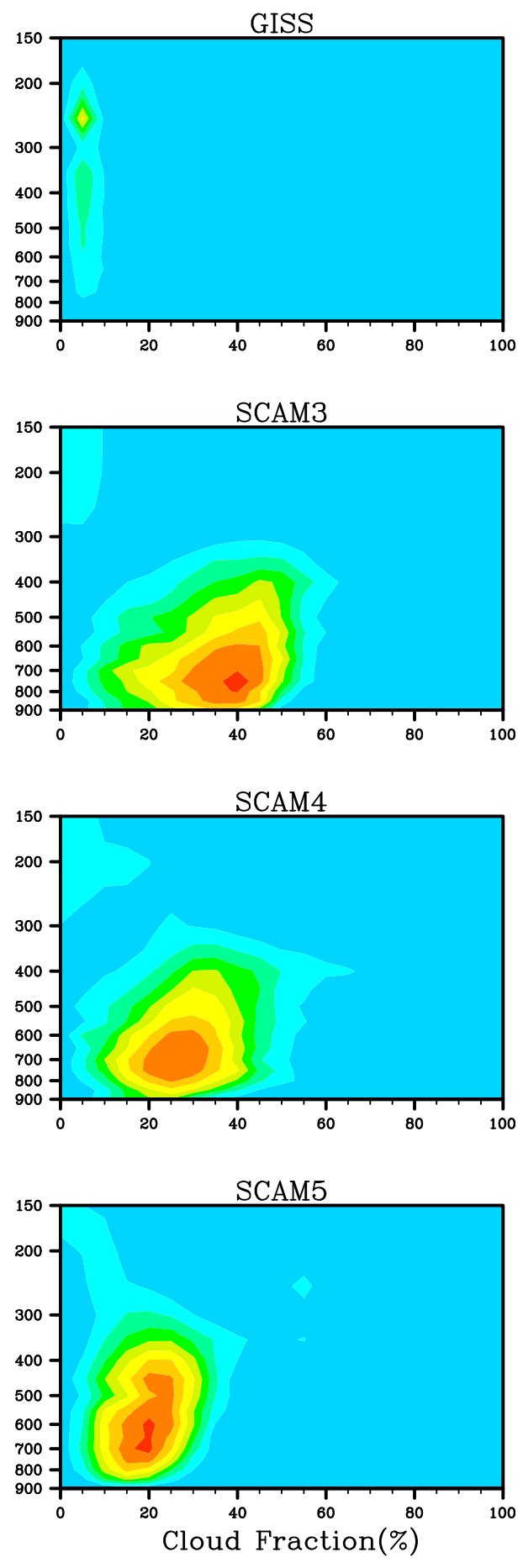

$$
f=1-\left(\frac{1-\bar{r}}{1-r_{c}}\right)^{1 / 2}
$$

where $f=0$ for $\bar{r} \leq r_{c}$ and $f=1$ for $\bar{r} \geq 1$. 
Using cloud fraction and RH from the models or observations, the threshold $\mathrm{RH}$ can be calculated $(0<f<1)$,

$$
r_{c}=1-\frac{1-\bar{r}}{(1-f)^{2}}
$$

Figure 9a shows the vertical profiles of the 3-yr mean threshold RH in the observations and the seven SCMs. Here the hourly RUC-based RH and hourly ARSCL cloud fraction are used to calculate the hourly threshold $\mathrm{RH}$ in the observations. It is seen that, compared with the observations, at levels below $400 \mathrm{hPa}$ all seven SCMs (except the GISS SCM at certain levels) have larger threshold RH, while at levels above $400 \mathrm{hPa}$ the two GFDL SCMs have smaller threshold RH and the ECMWF SCM and the three SCAMs still have larger threshold RH. The larger threshold RH in most SCMs also indicates their smaller subgrid variability of $\mathrm{RH}$ than the observations. The diagnosed threshold $\mathrm{RH}$ in Fig. 9a does not distinguish clouds of stratiform or nonstratiform. The nonstratiform clouds in the models are presumably produced by the convective schemes. Although the calculation of such clouds does not directly involve $\mathrm{RH}$, practically what constitutes the overall threshold RHs in Fig. 9a can be separated into those associated with stratiform and nonstratiform clouds. The vertical profiles of the diagnosed threshold $\mathrm{RH}$ for nonstratiform and stratiform events in the seven SCMs are shown in Fig. 9b. The values of threshold RH in the stratiform events are much larger than those in the nonstratiform events. This again implies that cumulus parameterizations do not use $\mathrm{RH}$ directly to form clouds (except to the extent that high PBL RH is needed for CAPE or buoyancy) and that such clouds often occur when the grid box as a whole, at least above the boundary layer, is drier than that needed to form stratiform clouds. It is also shown that the larger threshold RH values in most models (Fig. 9a) are mainly contributed by the threshold RHs of stratiform events, whereas the smaller threshold RH values in the GFDL SCMs at upper levels (Fig. 9a) are because of the higher ratio of nonstratiform events and the associated smaller threshold RH.

\section{b. Dependence of cloud fraction on $R H$}

The vertical profiles of mean cloud fraction binned by RH in the observations and seven SCMs are shown in Fig. 10 (shading). Note the RUC-based RH is used as the observation for the reasons discussed in section $2 \mathrm{~b}$. Cloud fraction increases with $\mathrm{RH}$ in both the observations and seven SCMs but more sharply at high $\mathrm{RH}$ ranges in most SCMs. Also, the model-observation differences in mean
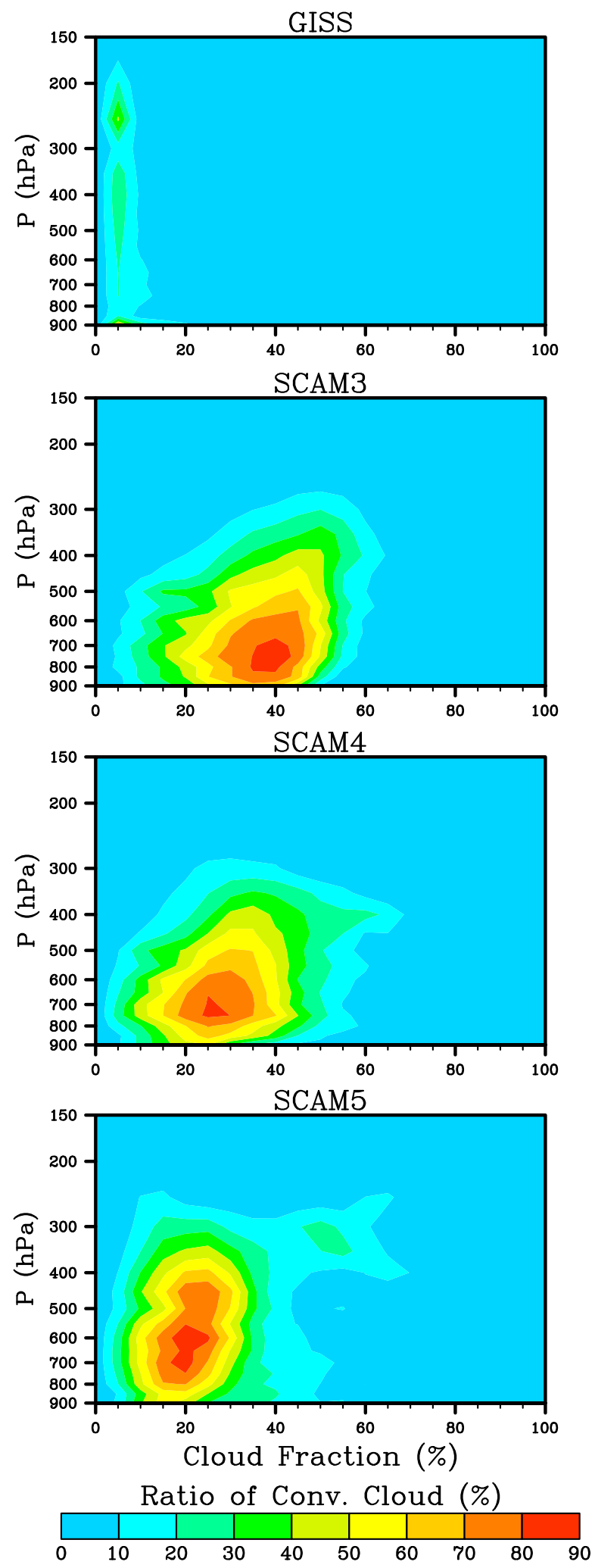

FIG. 8. Averaged ratios of the convective cloud fraction to total cloud fraction for each total cloud fraction bins (each bin is 5\%) in the GISS SCM and three SCAMs. Events with observed surface precipitation rate larger than $40 \mathrm{~mm} \mathrm{day}^{-1}$ are excluded. 

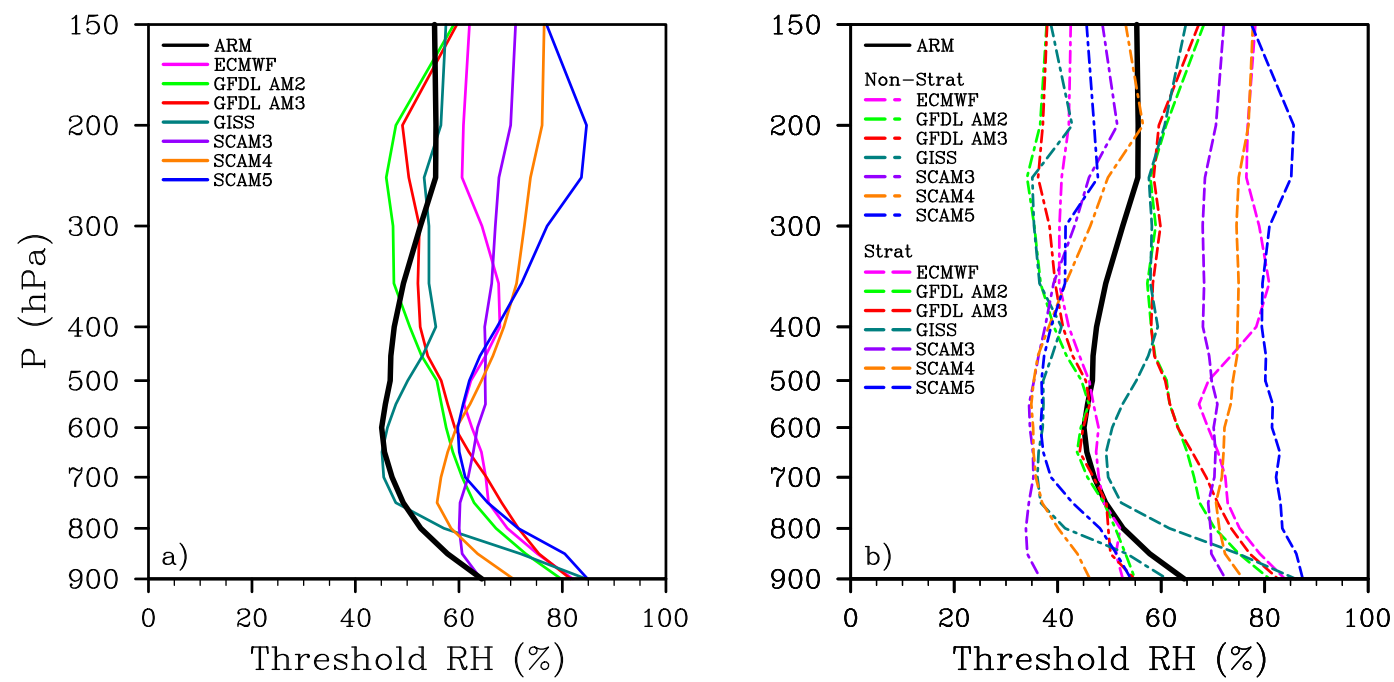

FIG. 9. (a) Vertical profiles of the diagnosed threshold RH in the observations and seven SCMs. (b) Vertical profiles of threshold RH in the ARM observations (black solid line) and seven SCMs for nonstratiform-source events (dashed-dotted lines) and for stratiform-source events (dashed lines). Events with observed surface precipitation rate larger than $40 \mathrm{~mm} \mathrm{day}^{-1}$ are excluded. The RUC-based $\mathrm{RH}$ data are used to derive threshold $\mathrm{RH}$ in the observations.

cloud fraction binned by RH (contours in Fig. 10) show large differences in the distribution patterns. In both the ECMWF and GISS SCMs, the mean cloud fractions at each RH bin are much smaller than the observations at most levels, which can be partly attributed to the weak dependence of cloud fraction on $\mathrm{RH}$ in these two models and generally larger RH threshold for stratiform clouds as shown in Fig. 9. Lack of nonstratiform cloud source at small cloud fractions in the GISS SCM (Fig. 7) also makes it unable to mitigate the negative biases. In the two GFDL SCMs at levels below $300 \mathrm{hPa}$, the mean cloud fractions are much smaller than the observations at most $\mathrm{RH}$ ranges, while at levels above $300 \mathrm{hPa}$ the mean cloud fractions are larger than the observations at all RH ranges, especially at the high RH ranges. In the three SCAMs, at lower levels mean cloud fractions at low RH ranges are slightly larger than observed. The positive cloud biases in GFDL and CAM SCMs at low-to-moderate $\mathrm{RH}$ ranges are most likely due to their excessive nonstratiform cloud production, while the negative biases at these low-tomoderate $\mathrm{RH}$ ranges may be primarily attributable to the requirement of higher RH threshold for stratiform clouds. Figure 11 shows the frequency distributions of RUC-based RH and modeled RH for each RH bins. It is seen that the distribution of $\mathrm{RH}$ favors low $\mathrm{RH}$ $(10 \%-40 \%)$ at lower-to-middle levels much more than at the upper levels. The ECMWF, two GFDL, and GISS SCMs have similar frequency distributions as that of the RUC-based RH, mainly with differences smaller than $1 \%$. However, the three SCAMs have significantly different frequency distributions of RH from those of the RUC-based RH (contours in Fig. 11) and other SCMs. There is a much higher frequency of large RH and a lower frequency of small RH, especially at levels above $500 \mathrm{hPa}$, in three SCAMs, indicating the strong overestimation of high-level RH. Combining the model-observation differences in mean cloud fraction and differences in RH distribution, it can be seen that the cause of upper-level cloud fraction in the seven SCMs differs substantially. In the ECMWF and GISS SCMs, the underestimation of upper-level cloud fraction may be primarily due to their weaker relationship between cloud fraction and RH. In the two GFDL SCMs, the overestimations of upper-level cloud fraction are mainly due to larger mean cloud fraction of cloudy events and more events, with $\mathrm{RH}$ ranging from $40 \%$ to $80 \%$ (Fig. S5 in the supplementary material). In the three SCAMs, the overestimation of upper-level cloud fraction is mainly due to the strong overestimation of RH. While the overestimation of lowerlevel clouds in SCAMs can be attributed to excessive convective cloud production, the underestimation of lower-level cloud fraction in the rest of SCMs may be primarily attributed to the fact that most events in the three years have RH smaller than threshold RH and models have larger threshold RH than the observations (Fig. 9).

It is noteworthy that we have also found that the relationship between cloud fraction and $\mathrm{RH}$ varies with 

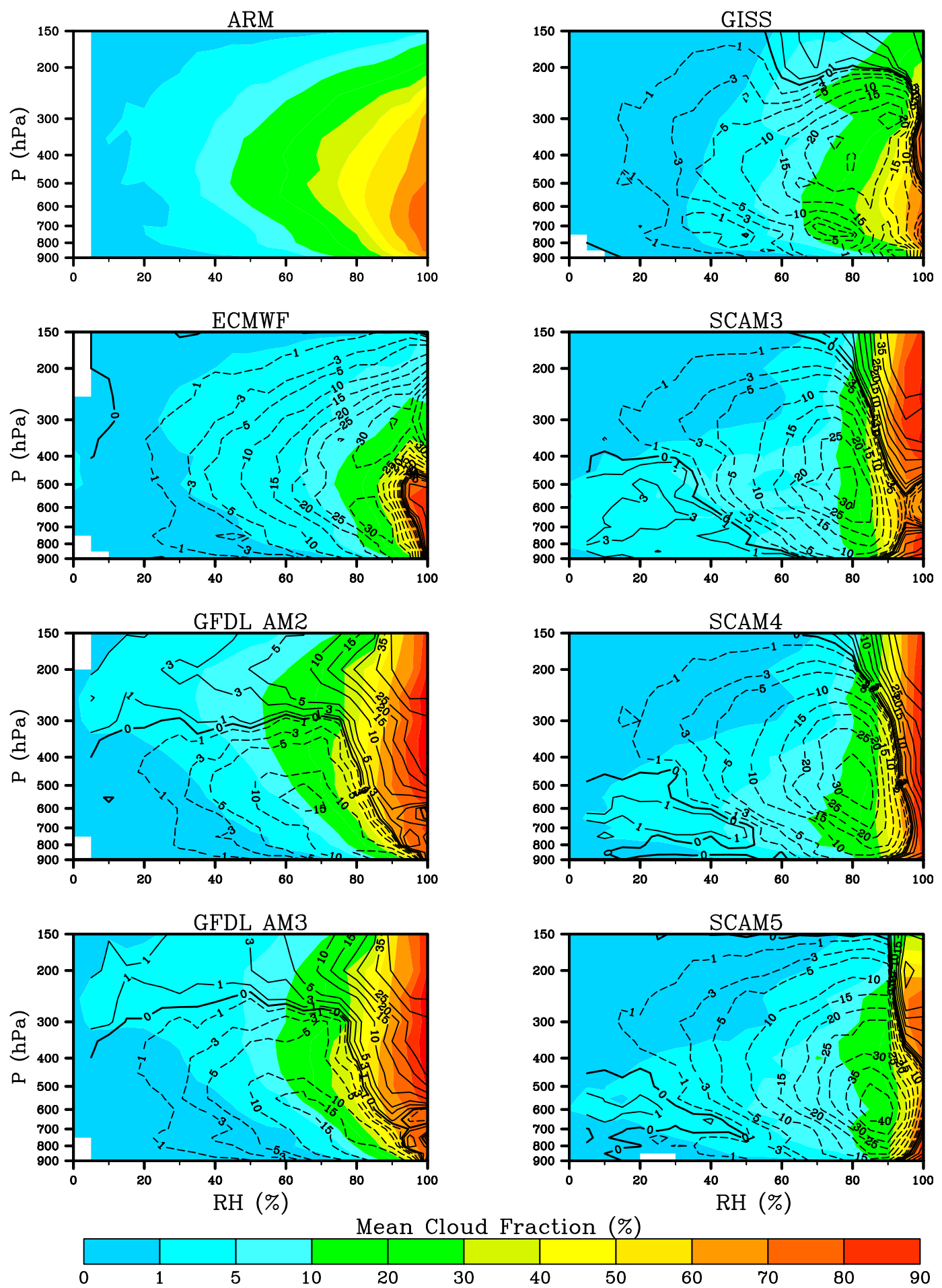

FIG. 10. Vertical profiles of mean cloud fraction in the ARM observations binned by the RUC-based RH and in seven SCMs binned by modeled RH (shading) and cloud fraction differences between the observations and seven SCMs (contours). Each bin of RH is $5 \%$. 

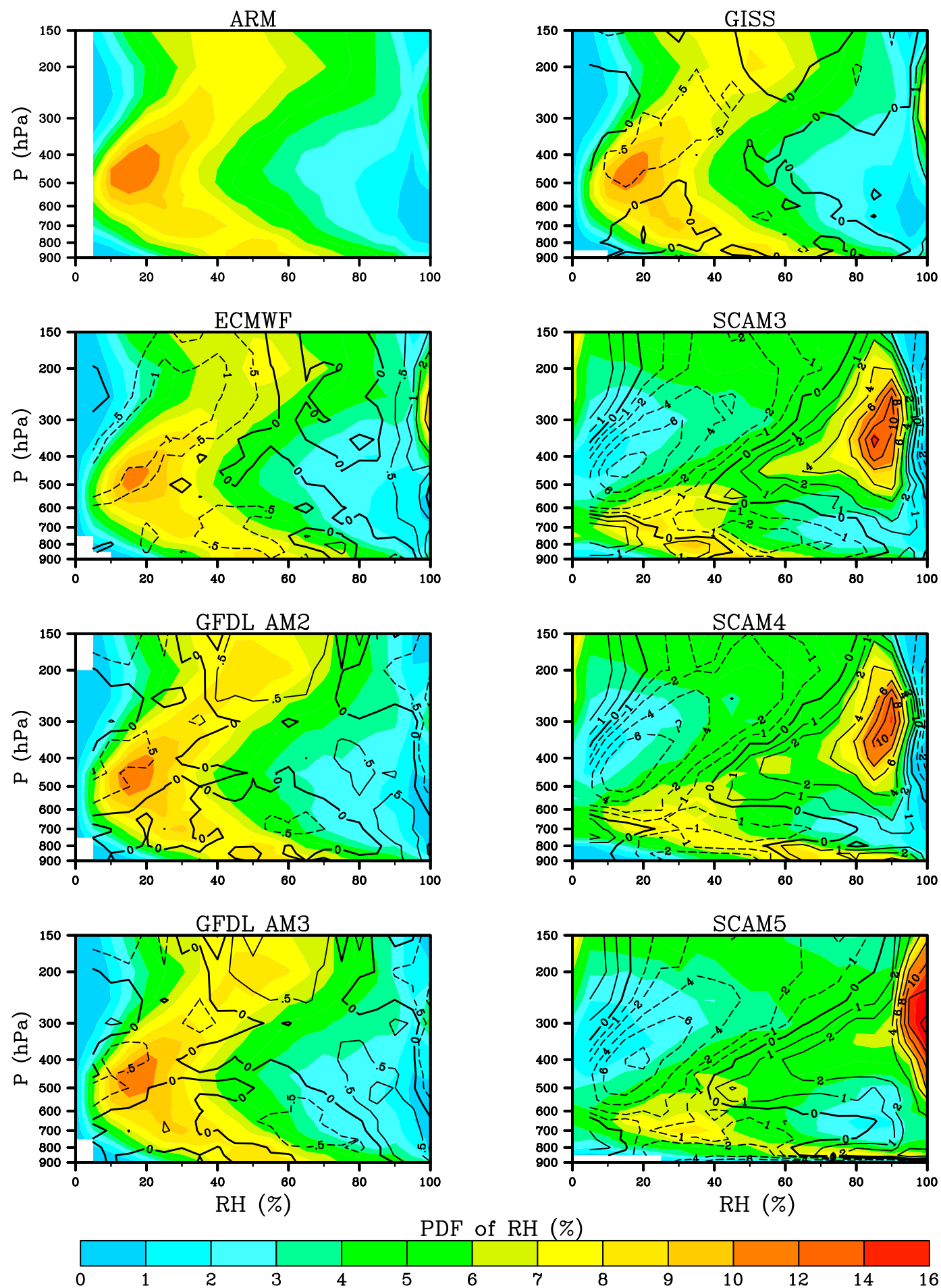

FIG. 11. As in Fig. 10, but for frequency of RH in the RUC-based forcing and seven SCMs. Events with observed surface precipitation rate larger than $40 \mathrm{~mm} \mathrm{day}^{-1}$ are excluded.

seasons in both observations and seven SCMs, with a tighter correlation in cold seasons when stratiform cloudy events dominate (Fig. S4 in the supplementary material). Meanwhile, cloud fraction has a much stronger relationship with RH in most SCMs than in the observations, which may be partially due to the fact that the RUC-based RH are not always well matched to the ARSCL point observations. 


\section{Summary}

This study quantitatively evaluates the overall performances of seven SCMs by comparing simulated cloud fraction with the observations at the ARM SGP site. Striking differences in cloud fraction are found not only between the SCMs and the observations but also among the SCMs themselves, in terms of mean cloud fraction and frequency distribution.

The seasonal and diurnal variation analyses demonstrate that the model-observation differences in cloud fraction are so persistent that the signs of the biases mostly last throughout the year and across the hours of the day, with the exception that the convection-induced lower-level positive biases in the SCAMs stand out during the daytime of the warm season. Compared with the 3-yr mean ARSCL cloud fraction, most of the SCMs overestimate upper-level cloud fraction and underestimate lower-level cloud fraction but still with some differences in details. The ECMWF SCM underestimates cloud fraction at all levels, and the GISS SCM underestimates cloud fraction at levels below $200 \mathrm{hPa}$. The GFDL SCMs underestimate lower-tomiddle-level cloud fraction but overestimate upper-level cloud fraction. The SCAMs overestimate upper-level cloud fraction and produce lower-level cloud fraction (600-800 hPa) similar to the observations. The SCAM3 and SCAM5 both overestimate midlevel cloud fraction while the SCAM4 underestimates. Also, the SCAM5 has more near-surface lower-level clouds than the observations and other SCMs.

The frequency distribution of cloud fraction shows a large discrepancy among the seven SCMs, especially between models with prognostic cloud fraction schemes and those with diagnostic cloud fraction schemes. Partitioning analysis further shows that the contribution of the stratiform process is much larger than that of the nonstratiform process to 3 -yr mean cloud fraction at all levels below $200 \mathrm{hPa}$ in all seven SCMs, indicating the importance of the stratiform process in producing cloud fraction in models. Despite a smaller contribution to the total cloud fraction, nonstratiform processes for cloud fraction production at different vertical levels and cloud fraction ranges are quite different among the seven SCMs. This large intermodel difference in nonstratiform processes seems consistent with that in convection parameterization and precipitation as reported in Song et al. (2013). Further analysis reveals different relationships between cloud fraction and $\mathrm{RH}$ in the models and observations. The consistent lower-level RH distribution in the SCMs and observations implies that the underestimation of lower-level cloud fraction in most SCMs is mainly due to the larger threshold $\mathrm{RH}$ used in the models, while biases in the upper-level cloud fraction for different SCMs exist for quite different reasons. Analysis of threshold RH suggests that there are substantial differences in the representation of subgrid variability among the seven models, and between the models and the observations. This finding reinforces the increasing recognition of the need for improving the representation of subgrid variability in climate models (Tompkins 2002; Wood and Hartmann 2006).

Compared to the precipitation performance reported in Song et al. (2013), the results show that unlike precipitation, the cloud fraction biases of the seven SCMs (stratiform cloud fraction for three SCAMs) are quite consistent during different seasons, daytime or nighttime. This is most likely related to the fact that, at the SGP site, the mean precipitation is dominated by convective precipitation whereas the mean cloud fraction is dominated by stratiform cloud fraction.

A few points are noteworthy. First, the continuous large-scale forcing used in our SCM simulations has some well-known limitations. For example, Kennedy et al. (2011) showed that the continuous forcing data have a moist bias in the boundary layer and at the upper levels, especially above $200 \mathrm{hPa}$, when compared to the ARMBE soundings (Fig. S1). This moist bias at the boundary layer likely influences the model convection process, especially for SCMs with CAPEbased triggers. Another deficiency is the lack of largescale hydrometeor advection in the continuous forcing data, which can influence modeled cloud fraction and precipitation through the prognostic cloud fraction scheme and/or prognostic cloud microphysical schemes. To further address possible influences of the forcing data on our SCM performances, simulations with an ensemble of long-term forcings will be carried out when different forcing data become available. Second, analysis of RH threshold in this study reveals some problems with the cloud fraction representation in climate models (e.g., $\mathrm{RH}$ representation and subgrid variability). Higher-resolution models such as cloud-resolving model or large-eddy simulations (e.g., Xu and Randall 1996b; Siebesma et al. 2003; Cheng and Xu 2011) can be used for further improving cloud parameterizations in GCMs. Finally, similar biases of cloud fraction identified in the seven SCMs at the SGP site can also be seen in some of their parent global models and many other GCMs (Qian et al. 2012; Fig. S6 in the supplementary material). Current cloud fraction schemes in models cannot well reproduce the observed cloud fraction (e.g., $\mathrm{Xu}$ and Randall 1996a; Lauer and Hamilton 2013). A better and more physically based cloud fraction scheme is 
needed to ultimately remove the deficiencies in climate models.

Acknowledgments. This work is supported by the Office of Biological and Environmental Research of the U.S. Department of Energy as part of the Earth Systems Modeling (ESM) program via the FASTER project (http://www.bnl.gov/faster) and Atmospheric System Research program. Del Genio is supported also by the NASA Modeling and Analysis Program. We thank Editor Dr. Robert Wood and three anonymous reviewers for their insightful and constructive comments. We also thank Dr. Stephen Schwartz for his interest and helpful suggestions.

\section{REFERENCES}

Ackerman, T. P., and G. M. Stokes, 2003: The Atmospheric Radiation Measurement Program. Phys. Today, 56, 38-44, doi:10.1063/1.1554135.

Anderson, J., and Coauthors, 2004: The new GFDL global atmosphere and land model AM2-LM2: Evaluation with prescribed SST simulations. J. Climate, 17, 4641-4673, doi:10.1175/JCLI-3223.1.

Boucher, O., and Coauthors, 2014: Clouds and aerosols. Climate Change 2013: The Physical Science Basis, T. F. Stocker et al., Eds., Cambridge University Press, 571-657.

Bretherton, C. S., J. R. McCaa, and H. Grenier, 2004: A new parameterization for shallow cumulus convection and its application to marine subtropical cloud-topped boundary layers. Part I: Description and 1D results. Mon. Wea. Rev., 132, 864-882, doi:10.1175/1520-0493(2004)132<0864:ANPFSC > 2.0.CO;2

Cess, R. D., and Coauthors, 1996: Cloud feedback in atmospheric general circulation models: An update. J. Geophys. Res., 101, 12 791-12794, doi:10.1029/96JD00822.

Cheng, A., and K.-M. Xu, 2011: Improved low-cloud simulation from a multiscale modeling framework with a third-order turbulence closure in its cloud-resolving model component. J. Geophys. Res., 116, D14101, doi:10.1029/2010JD015362.

Clothiaux, E. E., and Coauthors, 1999: The Atmospheric Radiation Measurement Program cloud radars: Operational modes. J. Atmos. Oceanic Technol., 16, 819-827, doi:10.1175/ 1520-0426(1999)016<0819:TARMPC >2.0.CO;2.

_, T. P. Ackerman, G. G. Mace, K. P. Moran, R. T. Marchand, M. A. Miller, and B. E. Martner, 2000: Objective determination of cloud heights and radar reflectivities using a combination of active remote sensors at the ARM CART sites. J. Appl. Meteor. 39, 645-665, doi:10.1175/1520-0450(2000)039<0645 $\mathrm{ODOCHA}>2.0 . \mathrm{CO} ; 2$

Davies, L., and Coauthors, 2013: A single-column model ensemble approach applied to the TWP-ICE experiment. J. Geophys. Res., 118, 6544-6563, doi:10.1002/jgrd.50450.

Del Genio, A. D., and A. Wolf, 2012: Should today's SCMs convect at the SGP? ASR Science Team Meeting, Arlington, VA, U.S. Department of Energy, 11 pp. [Available online at http://asr.science.energy.gov/meetings/stm/2012/presentations/ delgeniofaster.pdf.]

, M.-S. Yao, W. Kovari, and K. K.-W. Lo, 1996: A prognostic cloud water parameterization for global climate models. J. Climate, 9, 270-304, doi:10.1175/1520-0442(1996)009<0270: APCWPF $>2.0 . \mathrm{CO} ; 2$.
_ A. B. Wolf, and M. S. Yao, 2005: Evaluation of regional cloud feedbacks using single-column models. J. Geophys. Res., 110, D15S13, doi:10.1029/2004JD005011.

Dong, X., B. Xi, and P. Minnis, 2006: A climatology of midlatitude continental clouds from the ARM SGP Central Facility. Part II: Cloud fraction and surface radiative forcing. J. Climate, 19, 1765-1783, doi:10.1175/JCLI3710.1.

Donner, L. J., C. J. Seman, R. S. Hemiler, and S. Fan, 2001: A cumulus parameterization including mass fluxes, convective vertical velocities, and mesoscale effects: Thermodynamic and hydrological aspects in a general circulation model. J. Climate, 14, 3444-3463, doi:10.1175/1520-0442(2001)014<3444: ACPIMF $>2.0 . \mathrm{CO} ; 2$.

— , and Coauthors, 2011: The dynamical core, physical parameterizations, and basic simulation characteristics of the atmospheric component AM3 of the GFDL global coupled model CM3. J. Climate, 24, 3484-3519, doi:10.1175/2011JCLI3955.1.

Gettelman, A., and Coauthors, 2010: Global simulations of ice nucleation and ice supersaturation with an improved cloud scheme in the Community Atmosphere Model. J. Geophys. Res., 115, D18216, doi:10.1029/2009JD013797.

GEWEX Cloud System Science Team, 1993: The GEWEX Cloud System Study. Bull. Amer. Meteor. Soc., 74, 387-400, doi:10.1175/1520-0477(1993)074<0387:TGCSS >2.0.CO;2.

Ghan, S., and Coauthors, 2000: An intercomparison of single column model simulations of summertime midlatitude continental convection. J. Geophys. Res., 105, 2091-2124, doi:10.1029/1999JD900971.

Gregory, D., J. J. Morcrette, C. Jakob, A. C. M. Beljaars, and T. Stockdale, 2000: Revision of convection, radiation and cloud schemes in the ECMWF Integrated Forecasting System. Quart. J. Roy. Meteor. Soc., 126, 1685-1710, doi:10.1002/ qj. 49712656607.

Hahn, C. J., W. B. Rossow, and S. G. Warren, 2001: ISCCP cloud properties associated with standard cloud types identified in individual surface observations. J. Climate, 14, 11-28, doi:10.1175/1520-0442(2001)014<0011:ICPAWS >2.0.CO;2.

Henderson, P. W., and R. Pincus, 2009: Multiyear evaluations of a cloud model using ARM data. J. Atmos. Sci., 66, 2925-2936, doi:10.1175/2009JAS2957.1.

Kennedy, A. D., 2011: Evaluation of a single column model at the Southern Great Plains Climate Research Facility. Ph. D. dissertation, University of North Dakota, $149 \mathrm{pp}$.

$\longrightarrow$, X. Dong, B. Xi, P. Minnis, A. D. Del Genio, A. B. Wolf, and M. M. Khaiyer, 2010: Evaluation of the NASA GISS SingleColumn Model simulated clouds using combined surface and satellite observations. J. Climate, 23, 5175-5192, doi:10.1175/ 2010JCLI3353.1.

,,--- S. Xie, Y. Zhang, and J. Chen, 2011: A comparison of MERRA and NARR reanalysis datasets with the DOE ARM SGP continuous forcing data. J. Climate, 24, 4541-4557, doi:10.1175/2011JCLI3978.1.

Klein, S. A., and D. L. Hartmann, 1993: The seasonal cycle of low stratiform clouds. J. Climate, 6, 1587-1606, doi:10.1175/ 1520-0442(1993)006<1587:TSCOLS $>2.0$.CO;2.

, and Coauthors, 2009: Intercomparison of model simulations of mixed-phase clouds observed during the ARM MixedPhase Arctic Cloud Experiment. I: Single-layer cloud. Quart. J. Roy. Meteor. Soc., 135, 979-1002, doi:10.1002/qj.416.

Lauer, A., and K. Hamilton, 2013: Simulating clouds with global climate models: A comparison of CMIP5 results with CMIP3 and satellite data. J. Climate, 26, 3823-3845, doi:10.1175/ JCLI-D-12-00451.1. 
Lin, Y., and Coauthors, 2012: TWP-ICE global atmospheric model intercomparison: Convection responsiveness and resolution impact. J. Geophys. Res., 117, D09111, doi:10.1029/2011JD017018.

Minnis, P., Y. Yi, J. Huang, and K. Ayers, 2005: Relationships between radiosonde and RUC-2 meteorological conditions and cloud occurrence determined from ARM data. J. Geophys. Res., 110, D23204, doi:10.1029/2005JD006005.

Moorthi, S., and M. J. Suarez, 1992: Relaxed Arakawa-Schubert: A parameterization of moist convection for general circulation models. Mon. Wea. Rev., 120, 978-1002, doi:10.1175/ 1520-0493(1992)120<0978:RASAPO > 2.0.CO;2.

Morrison, H., and Coauthors, 2009: Intercomparison of model simulations of mixed-phase clouds observed during the ARM Mixed-Phase Arctic Cloud Experiment. II: Multilayer cloud. Quart. J. Roy. Meteor. Soc., 135, 1003-1019, doi:10.1002/ qj. 415.

Naud, C. M., A. D. Del Genio, M. Bauer, and W. Kovari, 2010: Cloud vertical distribution across warm and cold fronts in CloudSat-CALIPSO data and a general circulation model. J. Climate, 23, 3397-3415, doi:10.1175/2010JCLI3282.1.

Neggers, R. A. J., A. P. Siebesma, and T. Heus, 2012: Continuous single-column model evaluation at a permanent meteorological supersite. Bull. Amer. Meteor. Soc., 93, 1389-1400, doi:10.1175/BAMS-D-11-00162.1.

Qian, Y., C. N. Long, H. Wang, J. M. Comstock, S. A. McFarlane, and S. Xie, 2012: Evaluation of cloud fraction and its radiative effect simulated by IPCC AR4 global models against ARM surface observations. Atmos. Chem. Phys., 12, 1785-1810, doi:10.5194/acp-12-1785-2012.

Quaas, J., 2012: Evaluating the "critical relative humidity" as a measure of subgrid-scale variability of humidity in general circulation model cloud cover parameterizations using satellite data. J. Geophys. Res., 117, D09208, doi:10.1029/ 2012JD017495.

Randall, D. A., and D. G. Cripe, 1999: Alternative methods for specification of observed forcing in single-column models and cloud system models. J. Geophys. Res., 104, 24527-24545, doi:10.1029/1999JD900765.

_ , K.-M. Xu, R. J. C. Somerville, and S. Iacobellis, 1996: Singlecolumn models and cloud ensemble models as links between observations and climate models. J. Climate, 9, 1683-1697, doi:10.1175/1520-0442(1996)009<1683:SCMACE > 2.0.CO;2.

Rasch, P. J., and J. E. Kristjansson, 1998: A comparison of the CCM3 model climate using diagnosed and predicted condensate parameterizations. J. Climate, 11, 1587-1614, doi:10.1175/1520-0442(1998)011<1587:ACOTCM>2.0.CO;2.

Schmidt, G. A., and Coauthors, 2006: Present-day atmospheric simulations using GISS ModelE: Comparison to in situ, satellite, and reanalysis data. J. Climate, 19, 153-192, doi:10.1175/ JCLI3612.1.

Siebesma, A. P., and Coauthors, 2003: A large eddy simulation intercomparison study of shallow cumulus convection. $J$. Atmos. Sci., 60, 1201-1219, doi:10.1175/1520-0469(2003)60<1201: ALESIS > 2.0.CO;2.

Slingo, J. M., 1987: The development and verification of a cloud prediction scheme for the ECMWF model. Quart. J. Roy. Meteor. Soc., 113, 899-927, doi:10.1002/qj.49711347710.

_ 1980: A cloud parameterization scheme derived from GATE data for use with a numerical model. Quart. J. Roy. Meteor. Soc., 106, 747-770, doi:10.1002/qj.49710645008.

Solomon, S., D. Qin, M. Manning, Z. Chen, M. Marquis, K. Averyt, M. Tignor, and H. L. Miller Jr., Eds., 2007: Climate Change
2007: The Physical Science Basis. Cambridge University Press, 996 pp.

Song, H., W. Lin, Y. Lin, A. B. Wolf, R. Neggers, L. J. Donner, A. D. Del Genio, and Y. Liu, 2013: Evaluation of precipitation simulated by seven SCMs against the ARM observations at the SGPsite. J. Climate, 26, 5467-5492, doi:10.1175/JCLI-D-12-00263.1.

Stephens, G. L., and Coauthors, 2002: The CloudSat mission and the A-Train. Bull. Amer. Meteor. Soc., 83, 1771-1790, doi:10.1175/BAMS-83-12-1771.

Stokes, G. M., and S. E. Schwartz, 1994: The Atmospheric Radiation Measurement (ARM) program: Programmatic background and design of the cloud and radiation test bed. Bull. Amer. Meteor. Soc., 75, 1202-1221, doi:10.1175/1520-0477(1994)075<1201: TARMPP $>2.0 . \mathrm{CO} ; 2$.

Sundqvist, H., E. Berge, and J. E. Kristjánsson, 1989: Condensation and cloud parameterization studies with a mesoscale numerical weather prediction model. Mon. Wea. Rev., 117, 1641-1657, doi:10.1175/1520-0493(1989)117<1641: CACPSW $>2.0 . C O ; 2$.

Tiedtke, M., 1993: Representation of clouds in large-scale models. Mon. Wea. Rev., 121, 3040-3061, doi:10.1175/1520-0493(1993)121<3040: ROCILS $>2.0 . C O ; 2$.

Tompkins, A. M., 2002: A prognostic parameterization for the subgridscale variability of water vapor and clouds in large-scale models and its use to diagnose cloud cover. J. Atmos. Sci., 59, 1917-1942, doi:10.1175/1520-0469(2002)059<1917:APPFTS>2.0.CO;2.

_, K. Gierens, and G. Rädel, 2007: Ice supersaturation in the ECMWF integrated forecast system. Quart. J. Roy. Meteor. Soc., 133, 53-63, doi:10.1002/qj.14.

Turner, D. D., T. R. Shippert, P. D. Brown, S. A. Clough, R. O. Knuteson, H. E. Revercomb, and W. L. Smith, 1998: Longterm analyses of observed and line-by-line calculations of longwave surface spectral radiance and the effect of scaling the water vapor profile. Proc. Eighth Atmospheric Radiation Measurement Science Team Meeting, Tucson, AZ, U.S. Department of Energy, 773-776.

- B. M. Lesht, S. A. Clough, J. C. Liljegren, H. E. Revercomb, and D. C. Tobin, 2003: Dry bias and variability in Vaisala RS80$\mathrm{H}$ radiosondes: The ARM experience. J. Atmos. Oceanic Technol., 20, 117-132, doi:10.1175/1520-0426(2003)020<0117: DBAVIV $>2.0 . \mathrm{CO} ; 2$.

Vavrus, S., and D. Waliser, 2008: An improved parameterization for simulating Arctic cloud amount in the CCSM3 climate model. J. Climate, 21, 5673-5687, doi:10.1175/ 2008JCLI2299.1.

Wood, R., and D. L. Hartmann, 2006: Spatial variability of liquid water path in marine low cloud: The importance of mesoscale cellular convection. J. Climate, 19, 1748-1764, doi:10.1175/ JCLI3702.1.

Wu, J., A. D. Del Genio, M.-S. Yao, and A. B. Wolf, 2009: WRF and GISS SCM simulations of convective updraft properties during TWP-ICE. J. Geophys. Res., 114, D04206, doi:10.1029/ 2008JD010851.

Xie, S., and Coauthors, 2002: Intercomparison and evaluation of cumulus parameterizations under summertime midlatitude continental conditions. Quart. J. Roy. Meteor. Soc., 128, 10951135, doi:10.1256/003590002320373229.

_ , R. T. Cederwall, and M. Zhang, 2004: Developing long-term single-column model/cloud system-resolving model forcing data using numerical weather prediction products constrained by surface and top of atmosphere observations. J. Geophys. Res., 109, D01104, doi:10.1029/2003JD004045. 
- and Coauthors, 2005: Simulations of midlatitude frontal clouds by single-column and cloud-resolving models during the Atmospheric Radiation Measurement March 2000 cloud intensive operational period. J. Geophys. Res., 110, D15S03, doi:10.1029/2004JD005119.

— - and Coauthors, 2010: Cloud and more: ARM climate modeling best estimate data. Bull. Amer. Meteor. Soc., 91, 13-20, doi:10.1175/2009BAMS2891.1.

Xu, K.-M., and S. K. Krueger, 1991: Evaluation of cloudiness parameterizations using a cumulus ensemble model. Mon. Wea. Rev., 119, 342-367, doi:10.1175/1520-0493(1991)119<0342 EOCPUA $>2.0 . \mathrm{CO} ; 2$

and D. A. Randall, 1996a: Evaluation of statistically based cloudiness parameterizations used in climate models. J. Atmos.
Sci., 53, 3103-3119, doi:10.1175/1520-0469(1996)053<3103: $\mathrm{EOSBCP}>2.0 . \mathrm{CO} ; 2$.

$\longrightarrow$, and - 1996b: A semiempirical cloudiness parameterization for use in climate models. J. Atmos. Sci., 53, 3084-3102, doi:10.1175/1520-0469(1996)053<3084:ASCPFU>2.0.CO;2. , and Coauthors, 2005: Modeling springtime shallow frontal clouds with cloud-resolving and single-column models. J. Geophys. Res., 110, D15S04, doi:10.1029/2004JD005153.

Zhang, M., and Coauthors, 2013: CGILS: Results from the first phase of an international project to understand the physical mechanisms of low cloud feedbacks in single column models. J. Adv. Model. Earth Syst., 5, 826-842, doi:10.1002/ 2013MS000246. 